\title{
\begin{tabular}{l|l} 
Mibraries & DSpace@MIT
\end{tabular}
}

MIT Open Access Articles

Fractures: Tension and Shear

The MIT Faculty has made this article openly available. Please share how this access benefits you. Your story matters.

As Published: https://doi.org/10.1007/s00603-020-02243-8

Publisher: Springer Vienna

Persistent URL: https://hdl.handle.net/1721.1/136917

Version: Author's final manuscript: final author's manuscript post peer review, without publisher's formatting or copy editing

Terms of use: Creative Commons Attribution-Noncommercial-Share Alike 


\section{Fractures: Tension and Shear}

Cite this article as: Herbert $\mathrm{H}$. Einstein, Fractures: Tension and Shear, Rock Mechanics and Rock Engineering https://doi.org/10.1007/s00603-020-02243-8

This Author Accepted Manuscript is a PDF file of an unedited peer-reviewed manuscript that has been accepted for publication but has not been copyedited or corrected. The official version of record that is published in the journal is kept up to date and so may therefore differ from this version.

Terms of use and reuse: academic research for non-commercial purposes, see here for full terms. https://www.springer.com/aam-terms-v1 


\title{
Fractures - Tension and Shear
}

\author{
Herbert H. Einstein \\ Department of Civil and Environmental Engineering \\ Massachusetts Institute of Technology \\ einstein@mit.edu
}

List of symbols

$\begin{array}{ll}\varepsilon_{v} & \text { Volumetric strain } \\ \varepsilon_{1} & \text { Major principal strain } \\ \varepsilon_{3} & \text { Minor principal strain } \\ \gamma & \text { Shear strain } \\ \sigma_{\mathrm{n}} & \text { Normal stress } \\ \tau & \text { Shear Stress }\end{array}$

Keywords

Fractures, mechanisms, experiments, models

Conflict of interest

None

Funding

The research underlying the presented work was funded by a variety of sponsors over the past two decades. The author received an honorarium by MTS to present the keynote lecture at the 2019 ARMA Symposium.

Acknowledgements

The research was conducted by many students, postdoctoral fellows and involved collaboration with colleagues. Their names are shown in Figure 1. The author would also like to thank the organizers of the 2019 ARMA Symposium and MTS for the invitation to present this keynote lecture.

Preamble

At the 2019 ARMA symposium, the author presented the MTS keynote lecture "Why Observe". by looking at two phenomena, namely, arching and rock fracture mechanisms. In this paper the part on fractures is presented in written form. Given the oral origin of this paper it is presented in a style that differs somewhat from the technical papers published in Rock Mechanics and Rock Engineering. Specifically, it relies on and refers to illustrations more so than usual. The emphasis on illustrations also reflects the intent of the keynote, namely to show the 
importance of observations. The author would like to take the opportunity to thank the organizers of the ARMA Symposium and MTS for allowing me to present the MTS keynote lecture. I would also like to mention that what is presented is based on the work of present and former students (Figure 1)

Figure 1 Acknowledgements and thanks to present and former students, postdocs and colleagues who have been involved in the work presented in this paper

\section{Abstract}

The paper applies the observation cycle to rock fracturing processes. Specifically, it repeats the observation cycle by going from the large (field) scale to increasingly detailed laboratory scales. With this it is possible to determine that what appear to be tensile or shear fractures on the large scale are produced through a combination of tensile and shear mechanisms on the smaller scale. This involves observations with a variety of techniques that are briefly described. What is also emphasized is that observation has to go hand in hand with abstraction i.e. modeling to help understand the observed phenomena. The paper, therefore, makes two contributions $-a$ better understanding of rock fracturing processes and showing the importance of the observation cycle in a scientific process.

\section{Introduction}

As indicated in the preamble, the intent of the paper is twofold: 1 . Show the importance of observation in the context of the scientific method; 2 . Use this approach to investigate the occurrence of tension and shear mechanisms in the fracturing process. 
The observation cycles in Science and Engineering are shown in Figure 2. The Engineering application is the "Observational Method" (Terzaghi, 1961; Peck, 1969) to which this author has contributed through formalization if the updating process (Einstein, 2008). The scientific observation cycle can be used in the classic approach namely starting with a hypothesis and accepting, rejecting or updating it. However, it is also possible to start with the observation and interpret it to come up with a hypothesis or interpretation. Although not certain it seems possible that Archimedes discovered the buoyancy principle like this? This use of the observation cycle is also what is done today in most data driven approaches. Starting with observation was also done in the MTS lecture and now in this paper.

Figure 3 Persistence - Fractures consist of fractures and intact rock bridges.

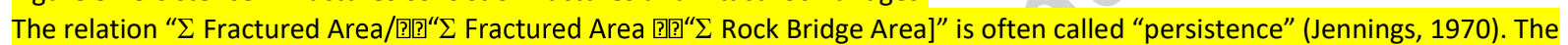
figure is a schematic two-dimensional representation of persistence.

Specifically, the observation that intact rock bridges exist, often characterized as persistence (see Figure 3), and how they break or fracture is the basic phenomenon that one likes to interpret. This fracturing can occur in tension, shear or combinations. The fracturing process also involves movement of existing fractures, i.e. opening or closing them or sliding along them. All this will be considered by applying the observation cycle several times, starting with the field evidence and eventually going to the laboratory and always involving abstraction, i.e. modeling. With this, some insight into the fundamental tension and shear mechanisms can be gained. Specifically, the paper will start by looking at field scale phenomena showing with this that the above-mentioned mechanisms exist and can be represented in a model (Section 2). Since it is possible to show that similar phenomena as in the field can also be observed on a smaller scale laboratory experiment are then presented (Section 3). They have the advantage that the loading conditions and material can be controlled. These tests show when tensile or shear fractures occur and can again be abstracted in a model. The laboratory investigation is then (Section 4) extended using real material and advanced observation methods (high-speed video, acoustic emissions) recording the mechanisms in detail - and again being able to distinguish shear and tension. Section 5 then briefly extends these laboratory experiments to hydraulic fracturing where the distinction between shear and tensile mechanisms is particularly 
important. As has been indicated and as will be seen in detail, the observational cycle is repeated with increasing refinement. The conclusions (Section 6) will, therefore, not only present what we found regarding shear or tensile mechanisms but also emphasize the use of the observation cycle when solving a scientific problem.

Figure 4 Persistence effect - single fracture plane The plane has an inclination that favors instability through sliding, but the rock mass is stable because of intact rock bridges.

Figure 5 Persistence effect - multiple parallel fracture planes The parallel planes have an inclination that favors instability through sliding, but the rock mass is stable because of intact rock bridges.

Figure 6 Persistence effect - multiple planes Two types (sets) of fractures exist, one vertical and one roughly inclined at $45^{\circ}$. These fractures create rock blocks that are unstable (fall off) if the factures are persistent (no intact rock bridges) but are stable with intact rock bridges.

a. General view of slope;

b. Closer view of slope with fallen blocks near the road and stable block above (see Fig.7).

Figure 7 Persistence effect - multiple planes

Close-up of Figure 6 showing stable block, fractures and intact rock bridge.

Figure 8 Persistence (intact rock bridge) effect on flow

Flow occurs from the closed (small aperture) fracture while there is none from the fracture with the larger aperture. The larger aperture made it possible to probe the fracture at depth, which revealed an intact rock bridge.

We then need to conceptually understand what is going on as schematically shown in Figure 9 and then try to further understand it with abstraction (modeling). For fracturing processes one often models the geometry and mechanisms separately before eventually combining them. Modeling geometry has to reflect the fact that isolated fractures and intact rock bridges exist. 
This is often done with stochastic discrete fracture models (DFM) such as GEOFRAC shown in Figure 10 or Fracman (Dershowitz, 1985; Doe et al., 2014).

Figure 9 Conceptual model of persistence (intact rock bridge) effects. The diagrams show existing fractures with continuous lines and possible interconnections (new fractures) through the intact rock bridges with dashed lines. $a$ and $b$. Instability can occur if the existing fractures are connected with new fractures through the intact rock bridges.

c. Schematic of a well intersecting an existing fracture. Flow to/from the isolated existing factures to the well requires new fractures through the intact rock bridge.

Figure 10 Modeling Geometry with the stochastic DFN model GEOFRAC (after Ivanova et al. 2014). GEOFRAC can represent fractures and intact rock bridges. This is done with a stepwise process:

- Modeling fracture planes representing fracture orientation distributions (primary process);

- modeling fractures and intact rock using Voronoi tessellation and fracture intensity measures such as $P_{32}$ (secondary process);

- then rotating and translating the individual fractures (tertiary process).

A well-suited mechanical model that will be further used in this paper is based on what Lajtai (1969) proposed and which is shown in Figure 11, using the Mohr envelope and Mohr Circles. With this model one can distinguish failures in "shear only", "tension only" or "combinations of shear and tension". At this point one needs to repeat the observational cycle to check in the field if these mechanisms really occur.

Figure 11 Modeling Mechanics - Different mechanisms; after Lajtai 1969

One can indeed observe natural tensile failure as already done by Woodworth (1896). Figure 12 shows the classic fractographic characterization of a tension joint/fracture as defined by Woodworth and then later expanded by many others (Kulander et al. 1979). Recognizing tensile fractography with visual observations allows one to determine the tensile origin of fractures. 
Figure 12 Typical fractography of a tension joint in Cambridge Argillite (after Woodworth, 1896) [Similar fractography will be seen in Figures 13 and 14 and on tensile fractures produced in laboratory experiments - see Figure 21].

These features can be clearly seen in the photographs taken in the Eidfjord in Norway (Figures 13 and 14) on joints (fractures) that were created through stress-relief after glacial valley cutting, essentially shifting the Mohr circle from a confined to an unconfined condition and thus producing tensile fractures. This mechanism will be demonstrated with laboratory experiments in Section 3. Fractures created in shear characterized by uneven/rough surfaces can also be observed (Figure 15); an explanation why shear surfaces can be rough will be provided in the following section on laboratory experiments. As to be expected, given the usual fracture geometry in the field shearing on one set of fractures occurs with tensile separation on surfaces perpendicular or steeply inclined relative to the shear surfaces. Figure 15 already indicates this but it is also evident in Figure 16 for natural slopes while Figure 17 shows this for typical wedge failures in a quarry.

Figure 13 Tensile fracturing in the slopes along Eidfjord Norway - overview. The photo shows that the fracturing has been caused by glacial valley cutting followed by stress relief after the glaciers disappeared.

Figure 14 Tensile fracturing in the slopes along Eidfjord Norway - close-up. The photo shows the typical tensile fractography similar to Figure 12 but larger.

Figure 15 Rough surface - the inclination of the surface indicates that it was probably created by sliding in shear.

Figure 16 Combined shear/tensile failure in a natural slope Figure 17 Combined shear/tensile failure in a quarry slope

It is thus possible to see the tension and shear mechanism in the field, and it is now desirable to go a step further by controlling the conditions that produce the different mechanisms, and this can be done in laboratory tests. 


\section{Laboratory Tests}

The observation cycle is applied again and Figures 18 and 19 present the phenomena on the laboratory scale. Specifically, Figure 18 shows the tensile fractography and Figure 19 slickensides characterizing shear on laboratory size specimens.

Figure 18 Tensile fractography in laboratory experiment Figure 19 Slickensides (shear) on a hand sized piece

This means that the concept and specifically the mechanical model (Figure 11) used for the field scale might be applicable also on the laboratory scale. This requires testing as done by the author's research group (and clearly many others). Figure 20 is a photo of a specimen with two pre-existing flaws subject to unconfined compression. The resulting cracks (fractures) are the classic tensile wing cracks propagating from the flaw tips in the direction of the major principal stress (vertical) and a shear crack between the flaws. The type of cracking is confirmed by the fractography, namely, plumose features for the tensile crack (Figure 21) and steps/slickensides for the shear crack (Figure 22). The vertical tensile (wing) crack corresponds to what has been discussed in Section 2 regarding the tensile fractures in the Eidfjord.

Figure 20 Prismatic gypsum specimen $10 \times 5(\times 2.5) \mathrm{cm}$ with preexisting flaws $(\mathrm{l}=1.25 \mathrm{~cm})$ subjected to uniaxial stress in vertical direction. Failure in tension and shear

Figure 21 View of fractography of specimen shown in Fig 20 Note plumose features characterizing tensile fracture

Figure 22 Close-up view of slickenside-fractography of specimen shown in Fig 20. Note steps in shear fracture - steep side against movement

The steps in Figure 22 are particularly interesting since the steep side is oriented against the movement. This has also been observed by Paterson (1958) and duplicated in early experiments of the MIT group (Bruhn, 1969). As will be seen when discussing below the tests by Riedel (1929) and Cloos (1955) below, this can be theoretically explained. To conclude the 
initial laboratory observation cycle, one can state that the model in Figure 11 is applicable to the phenomena and thus to the mechanisms observed on the laboratory scale.

While both the field observations and the laboratory tests confirm the existence of tensile and shear fractures and thus the applicability of the model, all this evidence is post-facto. In other words, we still do not know if a tensile fracture involves tensile mechanisms only or a combination of tensile and shear mechanisms and this analogically for shear fractures. One can get further evidence through observations during the experiments. This leads to the classic shearing experiments by Riedel (1929) and Cloos (1955). Both used $5 \mathrm{~cm}$ thick sheets of clay, in which either a thin water film existed on the surface (called "wet" below) or with no such film (called "dry" below). The suction effect in the dry case made this material more resistant (stronger) than the wet specimen. Most importantly, both Riedel and Cloos used sequential photographs during the tests with which it was possible to determine if the induced crack opened in tension or slid in shear. What is different between the tests by Riedel and Cloos is that the former are direct shear tests (Fig. 23) while the latter are pure shear tests (Fig.24).

Figure 23 Direct shear tests by Riedel 1929

Figure 24 Pure shear tests by Cloos 1955 (note circle on specimen surface)

The results are very consistent as shown in Figs. 25 and 26 for Riedel and 27 and 28 for Cloos. The wet, i.e. "weak" material fails with tensile cracks while the dry "strong" material fails with shear cracks. What is particularly satisfactory (again using the observation cycle) is that this can be modeled with appropriately sized Mohr circles both regarding the "strength effect" of wet versus dry as well as regarding the observed crack orientation as shown in the abovementioned figures. Also important are the steps shown in Fig. 26. As already mentioned regarding Fig. 22, the steep sides are oriented against the movement. The most important takeaway from these test series is the fact that applied shearing conditions can produce both shear and tensile fractures. This phenomenon, which can be understood and modeled with the Mohr circles in Figs. 25-28, includes both shear and tension and requires, therefore, repeating the observation cycle with more detailed testing and observation. 
Figure 25 Results of Riedel's (1929) direct shear test on wet clay -Tensile cracks

Figure 26 Results of Riedel's (1-29) direct shear test on dry clay - Shear cracks

Figure 27 Results of Cloos' (1955) pure shear tests on wet clay - Tensile cracks (Note distorted circle - recall Fig 24 indicating pure shear mechanism

Figure 28 Results of Cloos' (1955) pure shear tests on dry clay - Shear cracks (Note distorted circle - recall Fig 24 indicating pure shear mechanism

The detailed testing and observation is possible with the modern technology available at MIT and shown in the photo (Fig. 29) and diagram (Fig.30) of the overall testing setup. Specifically, high speed video (up to 14,000 frames/sec), high-resolution photography (42 megapixels) and acoustic emissions recordings are used in addition to feedback control when applying uniaxial or biaxial external loading. As will be seen below, the high speed video recordings can be analyzed frame by frame, which allows one to determine the type of fracturing (shear, tension). Similarly, both high speed and high-resolution photography can be used to apply Digital Image Correlation with which it is again possible to distinguish shear and tensile displacements/strains. All this can be done during the test. It is then also possible to go to an even smaller scale with SEM but this only post-test.

Figure 29 Photo of testing equipment Figure 30 Schematic of testing equipment with control features

The detailed testing allows one to investigate the process zone and to specifically look into the type of cracking (shear, tension). The process zone can very often be observed in the form of "white patching", a term introduced in Wong and Einstein (2009 a and b). In these papers and the underlying research white patching was related to the occurrence of multiple micro-cracks that could be Identified with a magnifying glass or SEM but not by bare eye where one could only see a change of color i.e. "white patching". The micro-cracks eventually interconnected to 
create a crack that could be discerned by bare eye. This research was done on marble and gypsum but as discussed below white patching also occurs in granite. Figs 31 and 32 show the evolution of white patching in granite specimens having two flaws and being subjected to uniaxial compression "Diffuse white patching" is usually related to subsequent surface spalling while "linear white patching" is associated with crack propagation. Figures 33 and 34 show the development of white patching with a frame-by-frame analysis of the high-speed video observations. As indicated there, the high-speed observations reveal opening-tension shown in Fig. 33 and shearing in Fig. 34. This has been observed in numerous tests as reported in Morgan et al., 2013.

Figure 31 Diffuse "white patching" in granite from Morgan et al. 2013 Figure 32 Linear "white patching" in granite from Morgan et al. 2013

Figure 33 Frame by frame analysis of white patching in granite followed by opening of a crack in tension (from Morgan et al. 2013)

Figure 34 Frame by frame analysis of white patching in granite followed by a shear crack (from Morgan et al. 2013)

In two of these experiments, in which again tensile or shear cracking was observed with the high-speed camera, more detailed investigations using SEM followed. This reveals, as shown in Fig. 35, that what appears as a tensile or shear crack on the High Speed Video scale consists of both tensile and shear cracking on the smaller SEM scale.

Figure 35 Process Zone in granite - Investigation with Scanning Electron Microscopy (from Morgan et al. 2013)

This highly interesting observation of having both shear and tension fractures occurring was, therefore, further investigated with four point beam bending of a notched specimen (Figure 36). This is a classic test in which tensile failure is induced. It is also a slow test such that the visual observation can be done with the high-resolution camera rather than with the highspeed camera. In addition, it presented the opportunity to simultaneously make visual and $A E$ 
observations and relate them to each other. Also, all this has been done for both granite and shale providing a basis for comparison of two different materials.

Figure 36 Four point loading test on notched beam Use of visual observations (two cameras - front macro camera, back micro camera) and AE Observations with $8 \mathrm{AE}$ sensors $(150-400 \mathrm{kHz}$ peak) $5 \mathrm{MHz}$ acquisition magnitude

Figure 37 shows the visual observations analyzed with DIC and acoustic emissions. For this case, i.e. a definite tensile crack emanating from an existing notch, it is evident both visually and with $\mathrm{AE}$, that both shear and tensile mechanisms occur and this for both materials. There is, nevertheless, a material dependence in that the process zone in granite is much more extensive than the one in shale.

Figure 37 DIC (Digital Image correlation) and AE (acoustic emission) Observations of progressing microcracking in 4-Point beam bending tests on granite and shale

At this point one can thus make a statement that, for the materials investigated and the testing conditions used, tensile and shear cracking on a larger scale both involve tensile and shear mechanisms on a smaller scale. In the context of the objective of this paper, it is also evident that observations were essential to see and understand the phenomena.

The importance and relevance of observations and the observation cycle can be further investigated by looking at hydraulic fracturing. The overall equipment is the same as used before (Fig 30) but now also including the possibility to apply hydraulic pressure in the flaws and to observe the hydraulic fractures both with AE and visually (Fig. 38) with special equipment shown in Fig.39. This was again done for granite and shale.

Figure 38 Granite specimen with double flaws, loading platens and AE sensors 


\section{Figure 39 Pressurization device to produce hydraulic pressure in the flaws and} visually observe the fracturing/cracking process

The hydraulic fracturing tests were conducted on specimens with vertical flaws under uniaxial compression of $3.5 \mathrm{MPa}$ and hydraulic injection rates of $0.39 \mathrm{~mL} / \mathrm{sec}$ and $0.011 \mathrm{~mL} / \mathrm{sec}$., as shown in Fig 39. Details of these tests have been reported in Li (2019) and are being published in Li and Einstein (2019) To avoid duplication of publications, only the results of the $0.39 \mathrm{~mL} / \mathrm{sec}$ tests are reported here. (The observations regarding shear/tension are analogous to the other tests). Fig 40. shows strain and normal strain contours (color code) as well as displacement vectors determined with DIC.

Figure 39 Hydraulic fracturing test on a single vertical flaw Figure 40 Sequence of crack development in hydraulic fracturing test (Fig 39) visually observed and recorded with DIC

The figure presents time sequences showing how hydraulically induced cracks proceed from the tip of the flaw. Initially strains and displacement in both granite and shale are somewhat random with an interesting wedge shape appearance in shale Fig 41. Toward the end, however, the strains and displacements concentrate along a definite crack and, very importantly, both shearing and opening (tension) along the crack can be observed. The latter is expressed by compression outside the crack as indicated by the vectors. Fig 42 of the AE hypocenters confirms this. One can observe double-couple (shear) events as well as implosive (compression) and explosive (tension) events. They are aligned along the evolving cracks but the details are not as clear as for the visual observations given the different scale.

Figure 41 Same sequence as Fig 40 but with identification of wedge shaped strains Figure 42 Sequence of crack development of test shown in Fig 39 observed with AE

\section{Conclusions}


Two major conclusions can be drawn, one regarding the process and the other one regarding mechanisms:

The observational cycle should be used both in engineering and in science. The latter has been demonstrated here. What is most important is that it is a cycle and a cycle that needs to be repeated to increase the understanding of whatever is being investigated (in science) or built (in engineering). This has been shown for fracturing starting on the large scale and proceeding to smaller more detailed levels. In doing this, it has become clear that observations and abstractions (models) are equally important.

Regarding fractures and specifically the question of tension and shear, it was possible to show that both mechanisms occur often simultaneously at the same location, while, very importantly, on a larger scale the same feature often shows only one or the other. While this has been shown here for specific materials and specific loading conditions, it may not be so for other conditions, and this is the other paper's conclusions next to the one on the observation cycle: One must not generalize or be very careful when doing so.

Literature References

Bruhn R.W. (1969) The strength and deformability of a model rock with one set of joints perpendicular to a principal axis. MIT MSc thesis

Cloos E. (1955) Experimental analysis of fracture patterns. Bulletin of the Geological Society of America Vol 66

Dershowitz,W: Rock Joint Systems, PhD Dissertation, Massachusetts Institute of Technology, (1985).

Doe T., Mc Laren R., Dershowitz W. (2014) Discrete fracture network simulations of Enhanced Geothermal Systems, Proceedings, Thirty-Ninth Workshop on Geothermal Reservoir Engineering Stanford University 
Einstein, H.H. (2008). Reducing uncertainty through updating - from experiments to the observational method. In: Proceedings of the 11th ISRM Congress, 9-13 July, Lisbon, Portugal.

Ivanova, V.M., Sousa, R., Murrihy, B., and Einstein, H.H. (2014). Mathematical algorithm development and parametric studies with the GEOFRAC three-dimensional stochastic model of natural rock fracture systems. Computers \& Geosciences, 67

Jennings, J.E., "A mathematical theory for the calculation of the stability of slopes in open cast mines", Proc. Symp. on Planning Open Pit Mines, Johannesburg 1970, pp. 87-102.

Kulander,B.R, Barton C.C., Dean S.L. (1979) The application of fractography to core and outcrop fracture. US DOE Report METCSP-79/3

Lajtai E.Z. (1969) Strength of discontinuities in rock in direct shear Géotechnique Vol 19

Li, B. Q. (2019). Microseismic and real-time imaging of fractures and microfractures in Barre granite and Opalinus clayshale. Ph.D dissertation, Massachusetts Institute of Technology

Li, B.Q., Gonçalves da Silva, B.M., and Einstein, H.H. (2019). Laboratory hydraulic fracturing of granite: Acoustic emission observations and interpretation. Engineering Fracture Mechanics, 209, 200-220.

Li, B.Q., and Einstein, H.H. (2020). Normalized radiated seismic energy from laboratory fracture experiments on Opalinus Clayshale and Barre Granite. Journal of Geophysical Research: Solid Earth.

Li, B.Q., and Einstein, H.H. (2019). Direct and microseismic observations of hydraulic fracturing in Barre Granite and Opalinus Clayshale. Journal of Geophysical Research: Solid Earth, 124

Morgan, S.P., Johnson, C.A., and Einstein, H.H. (2013). Cracking processes in Barre granite: fracture process zones and crack coalescence. International Journal of Fracture, 180 (2),

Paterson M. (1958) Experimental deformation and faulting of Wombeyan marble. Bulletin Geological Society of America, Vol 69

Peck R.B. (1969) Advantages and Limitations of the Observational Method, Géotechnique, Vol 19 Issue 2

Riedel W.(1929 ) Zur Mechanik geologischer Brucherscheinungen Zentralblatt für Mineralogie Abt B pp 354-368

Terzaghi, K. (1961). "Past and future of applied soil mechanics." Journal BSCE, April 
Woodworth J.B. (1896), On the fracture systems of joints- with some remarks on great fractures. Proceedings Boston Society of Natural History

Wong, L.N.Y., and Einstein, H.H. (2009 a). Crack coalescence in molded gypsum and Carrara marble: Part 1. Macroscopic observations and interpretation. Rock Mechanics and Rock Engineering, 42 (3)

Wong, L.N.Y., and Einstein, H.H. (2009 b). Crack coalescence in molded gypsum and Carrara marble: Part 2. Macroscopic observations and interpretation. Rock Mechanics and Rock Engineering, 42 (3)

FIGURE HEADINGS MTS TALK corrected

1 Acknowledgements and thanks to present and former students, postdocs and colleagues who have been involved in the work presented in this paper.

2 Observation Cycle

Left: Scientific Observation Cycle; Right: Engineering Observation Cycle.

3 Persistence - Fractures consist of fractures and intact rock bridges. The 


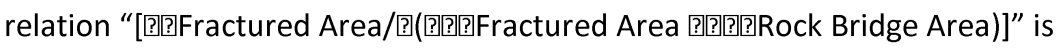
often called "persistence" (Jennings, 1970). The figure is a schematic twodimensional representation of persistence.

4 Persistence effect - single fracture plane

The plane has an inclination that favors instability through sliding, but the rock mass is stable because of intact rock bridges.

5 Persistence effect - multiple parallel fracture planes

The parallel planes have an inclination that favors instability through sliding, but the rock mass is stable because of intact rock bridges.

6 Persistence effect - multiple planes

Two types (sets) of fractures exist, one vertical and one roughly inclined at $45^{\circ}$. These fractures create rock blocks that are unstable (fall off) if the factures are persistent (no intact rock bridges) but are stable with intact rock bridges.

c. General view of slope;

d. Closer view of slope with fallen blocks near the road and stable block above (see Fig.7).

7 Persistence effect - multiple planes

Close-up of Figure 6 showing stable block, fractures and intact rock bridge.

8 Persistence (intact rock bridge) effect on flow

Flow occurs from the closed (small aperture at right) fracture while there is none from the fracture with the larger aperture (at left). The larger aperture made it possible to probe the fracture at depth, which revealed an intact rock bridge.

9 Conceptual model of persistence (intact rock bridge) effects.

The diagrams show existing fractures with continuous lines and possible interconnections (new fractures) through the intact rock bridges with dashed lines.

$a$ and $b$. Instability can occur if the existing fractures are connected with new fractures through the intact rock bridges.

c. Schematic of a well intersecting an existing fracture. Flow to/from the isolated existing factures to the well requires new fractures through the intact rock bridge.

10 Modeling Geometry with the stochastic DFN model GEOFRAC (after Ivanova et al. 2014)

GEOFRAC can represent fractures and intact rock bridges. This is done by a stepwise process:

- Modeling fracture planes representing fracture orientation distributions (primary process);

- modeling fractures and intact rock using Voronoi tessellation and fracture intensity measures such as $\mathrm{P}_{32}$ (secondary process);

- then rotating and translating the individual fractures (tertiary process).

11 Modeling Mechanics - Different mechanisms (after Lajtai, 1969)

12 Typical fractography of a tension joint in Cambridge Argillite (after 
Woodworth, 1896) [Similar fractography will be seen in Figures 13 and 14 and on tensile fractures produced in laboratory experiments - see Figure 21].

13 Tensile fracturing in the slopes along Eidfjord Norway - overview.

The photo shows that the fracturing has been caused by glacial valley cutting followed by stress relief after the glaciers disappeared.

14 Tensile fracturing in the slopes along Eidfjord Norway - close-up The photo shows the typical tensile fractography of figure 12 but larger

15 Rough surface - the inclination of the surface indicates that it was probably created by sliding in shear.

16 Combined shear/tensile failure in a natural slope

17 Combined shear/tensile failure in a quarry slope

18 Tensile fractography in laboratory experiment

19 Slickensides (shear) on a hand sized piece

20 Prismatic gypsum specimen $10 \times 5(\times 2.5) \mathrm{cm}$ with preexisting flaws $(I=1.25 \mathrm{~cm})$ subjected to uniaxial stress in vertical direction. Failure in tension and shear

21 View of fractography of specimen shown in Fig 20 Note plumose features characterizing tensile fracture

22 Close-up view of slickenside-fractography of specimen shown in Fig 20. Note steps in shear fracture - steep side against movement

23 Direct shear tests by Riedel 1927

24 Pure Shear tests by Cloos 1955 (note circle on specimen surface)

25 Results of Riedel's direct shear test on wet clay Tensile cracks

26 Results of Riedel's direct shear test on dry clay Shear cracks

27 Results of Cloos' pure shear tests on wet clay Tensile cracks

(Note distorted circle - recall Fig 24 indicating pure shear mechanism)

28 Results of Cloos' pure shear tests on dry clay Shear cracks

(Note distorted circle -recall Fig 24 indicating pure shear mechanism

29 Photo of testing equipment

30 Schematic of testing equipment with control features. 
31 Evolution of "white patching" in granite from Morgan et al. 2013

32 Linear and diffuse "white patching" in granite from Morgan et al. 2013

33 Frame by frame analysis of white patching in granite followed by opening of a crack in tension (from Morgan et al. 2013)

34 Frame by frame analysis of white patching in granite followed by a shear crack (from Morgan et al. 2013)

35 Process zone in granite Investigation with Scanning Electron Microscopy (from Morgan et al. 2013)

36 Four point loading test on notched beam

Use of visual observations (two cameras - front macro camera, back micro camera) and

AE Observations with $8 \mathrm{AE}$ sensors (150-400 kHz peak) $5 \mathrm{MHz}$ acquisition magnitude

37 DIC (Digital Image correlation) and AE (acoustic emission) Observations of progressing microcracking in 4-Point beam-bending tests on granite and shale

38 Granite specimen with double flaws, loading platens and AE sensors

39 Hydraulic fracturing test on a single vertical flaw

40 Sequence of crack development in hydraulic fracturing test (Fig 39) visually observed and recorded with DIC

41 Same sequence as Fig 40 but with identification of wedge shaped strains

42 Sequence of crack development of test shown in Fig 39 observed with $A E$ 


\section{Thanks to}

\begin{tabular}{lll} 
Omar AlDajani & Gerald Iglesia & Jay Miller \\
Ignacio Arzuaga & Violeta Ivanova & Olivia Reyes \\
Antonio Bobet & Ray Janeiro & Arabelle de Saussure \\
Zenzile Brooks & Paul Joseph & Rita Sousa \\
Michela Casanova & Hao Kang & Rafael Villamor Lora \\
Bill Dershowitz & Karim Karam & Robert Whitman \\
$\begin{array}{c}\text { Victoire Denis du } \\
\text { Péage }\end{array}$ & Bing Li & Louis Wong \\
Jack Germaine & Wei Li & \\
Bruno Gonçalves da & Ariel Martinez & \\
\multicolumn{1}{c}{ Silva } & Steve Morgan & \\
& Omid Moradian &
\end{tabular}

Figure 1 Acknowledgements and thanks to present and former students, postdocs and colleagues who have been involved in the work presented in this paper. 


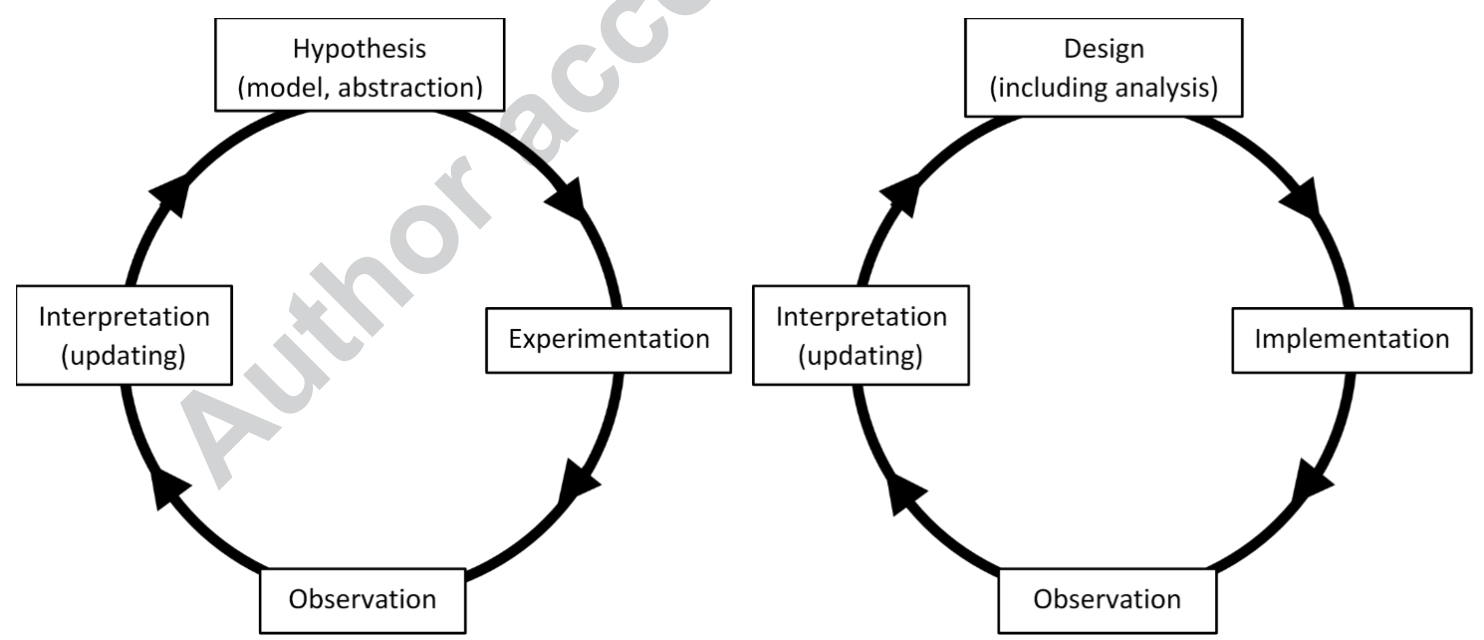

2. Observation Cycle Left - Scientific Observation Cycle; Right - Engineering Observation Cycle. 


\section{Persistence}

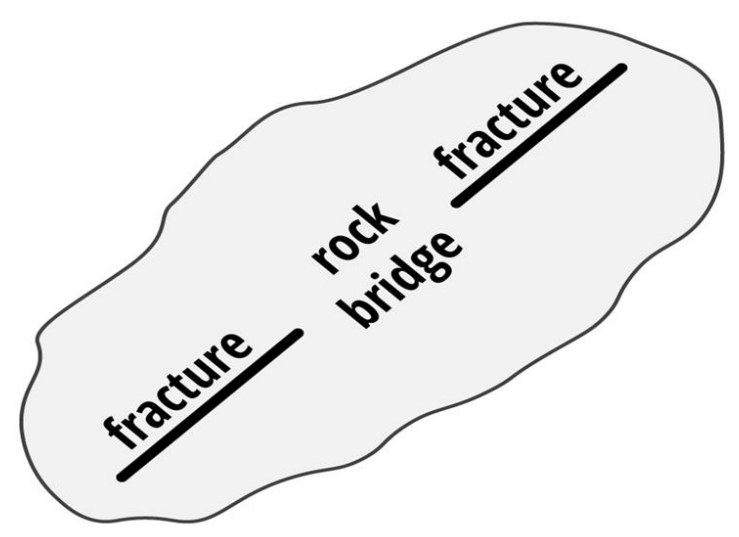

Figure 3 Persistence - Fractures consist of fractures and intact rock bridges.

The relation "[ $\Sigma$ Fractured Area/ $(\Sigma$ Fractured Area $+\Sigma$ Rock Bridge Area) $]$ " is often called "persistence" (Jennings, 1970). The figure is a schematic two-dimensional representation of persistence. 


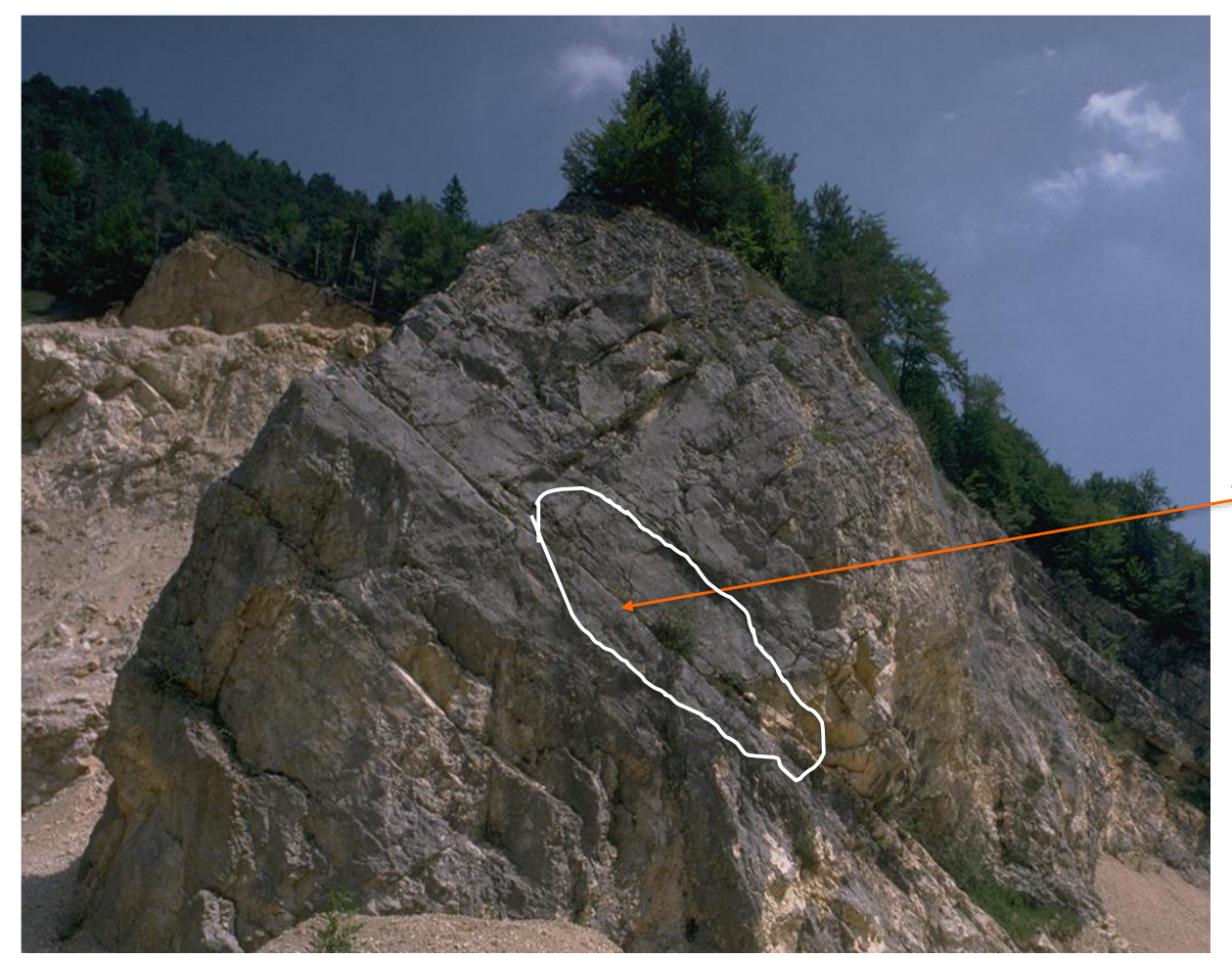

Persistence

Single

plane?

4 Persistence effect - single fracture plane

Figure The plane has an inclination that favors instability through sliding, but the rock mass is stable because of intact rock bridges. 


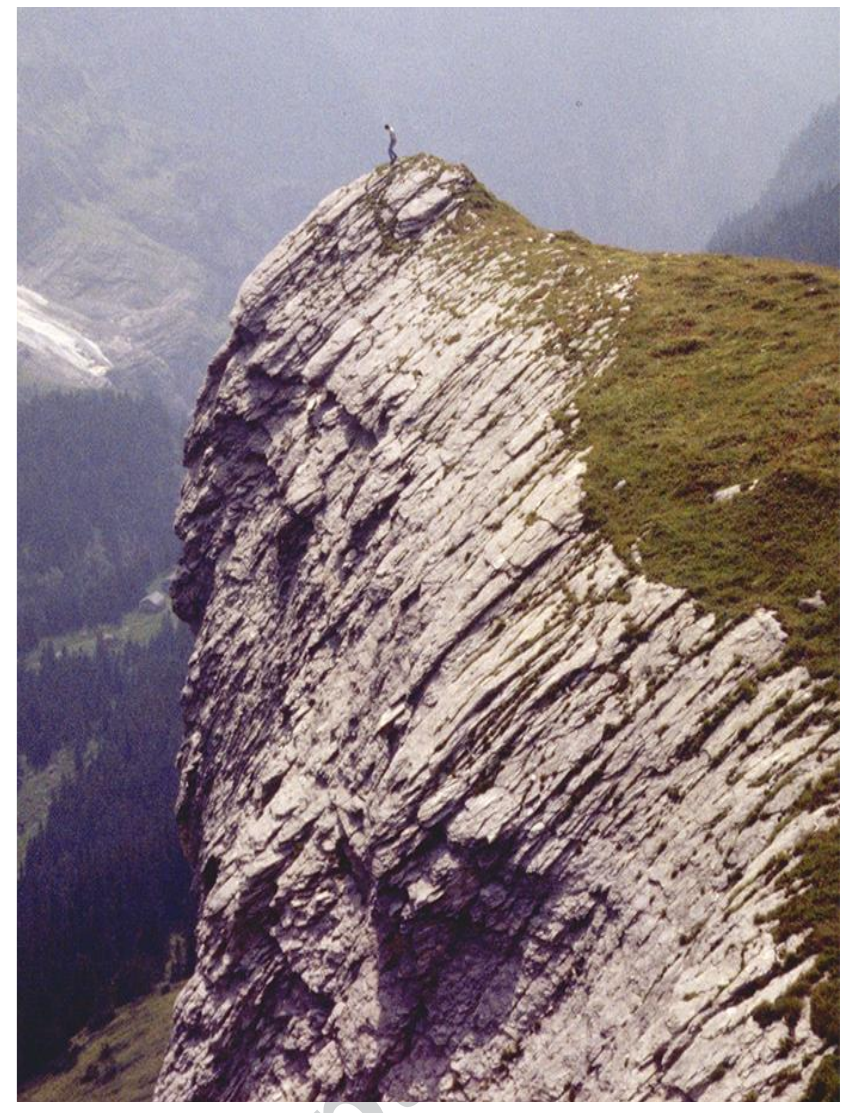

Figure 5 Persistence effect - multiple parallel fracture planes

The parallel planes have an inclination that favors instability through sliding, but the rock mass is stable because of intact rock bridges. 
a

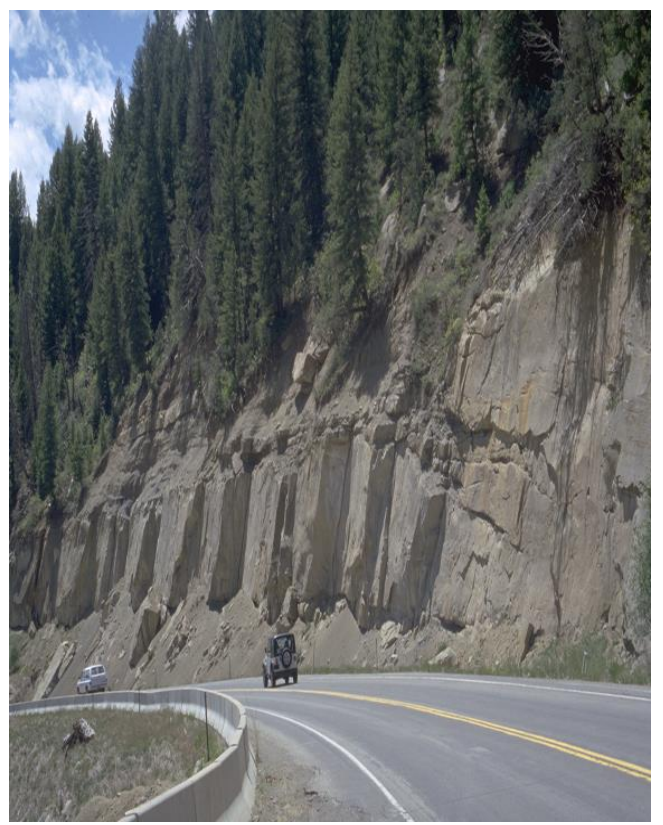

b

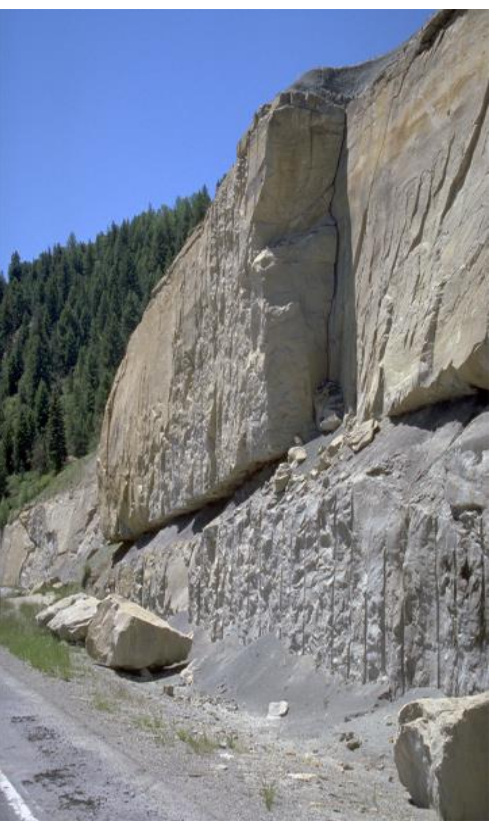

6 Persistence effect - multiple planes

Figure

Two types (sets) of fractures exist, one vertical and one roughly inclined at $45^{\circ}$. These fractures create rock blocks that are unstable (fall off) if the factures are persistent (no intact rock bridges) but are stable with intact rock bridges.

e. General view of slope;

f. Closer view of slope with fallen blocks near the road and stable block above (see Fig.7). 


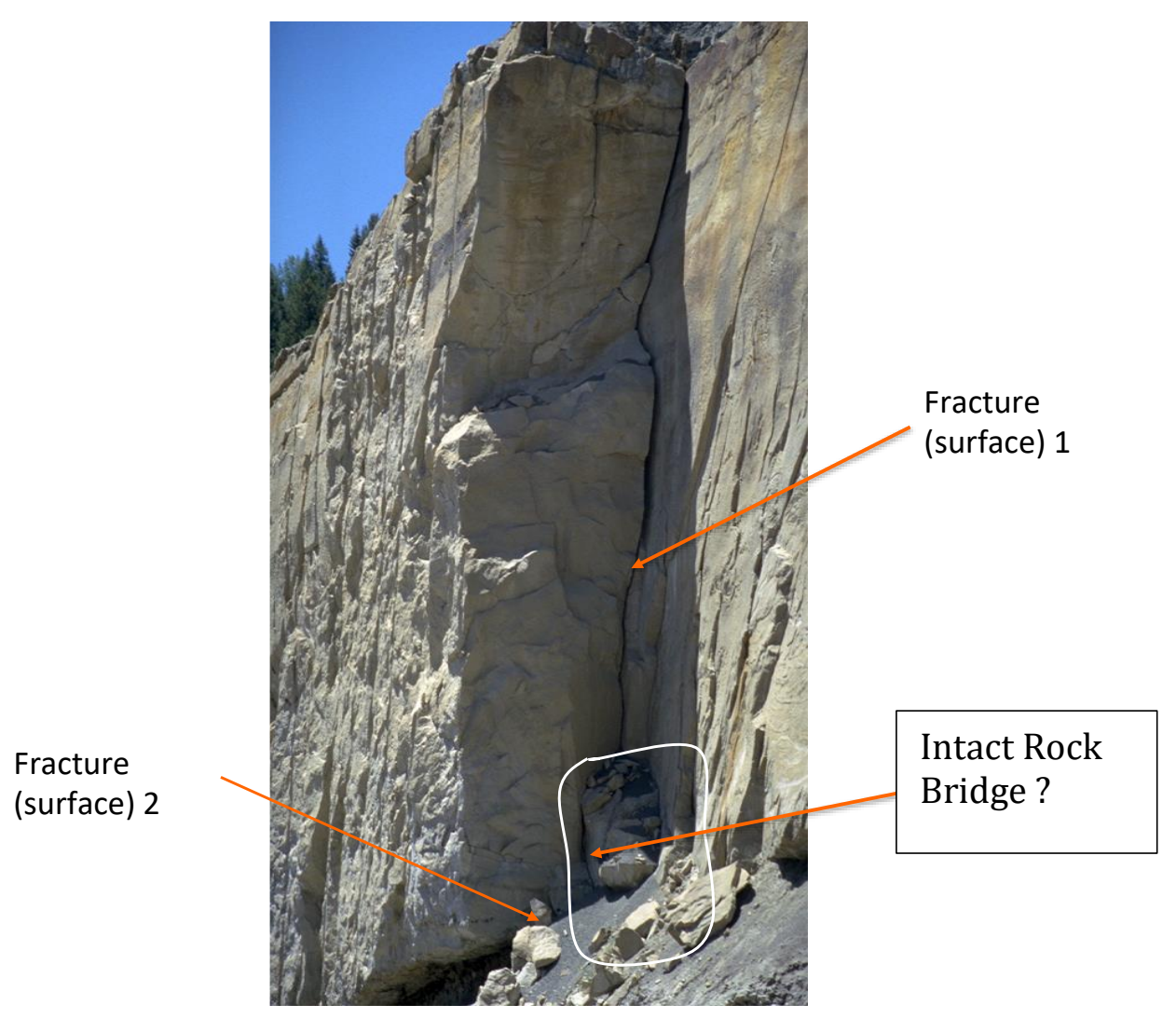

Figure 7 Persistence effect - multiple planes

Close-up of Figure 6 showing stable block, fractures and intact rock bridge. 


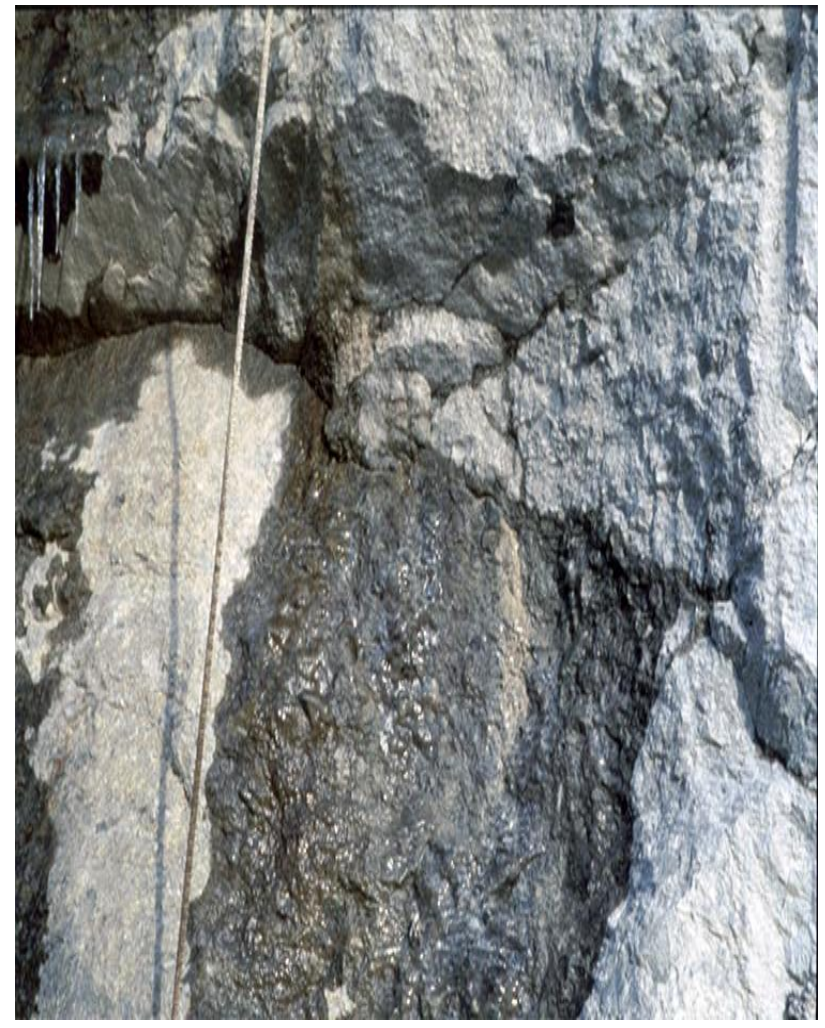

Figure 8 Persistence (intact rock bridge) effect on flow Flow occurs from the closed (small aperture at right) fracture while there is none from the fracture with the larger aperture (at left). The larger aperture made it possible to probe the fracture at depth, which revealed an intact rock bridge. 
Intact Rock Bridges

(A-B)

Affect stability

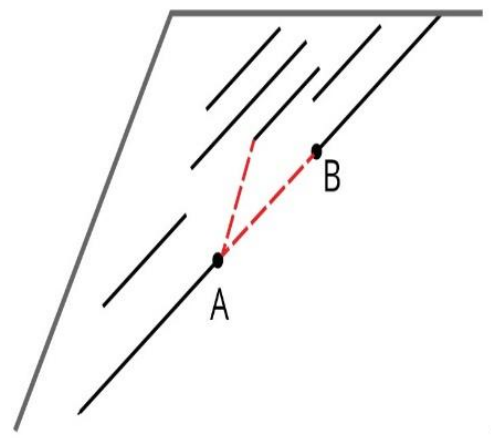

a)

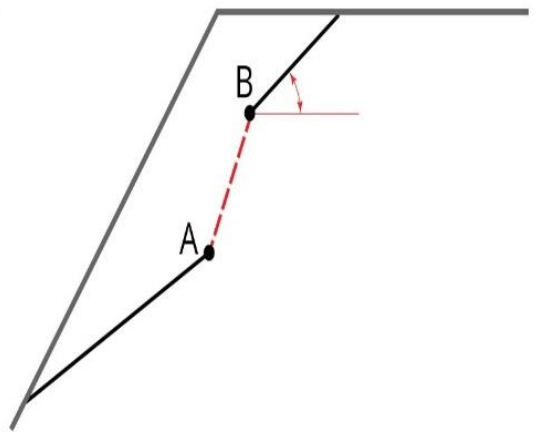

b)

Affect flow

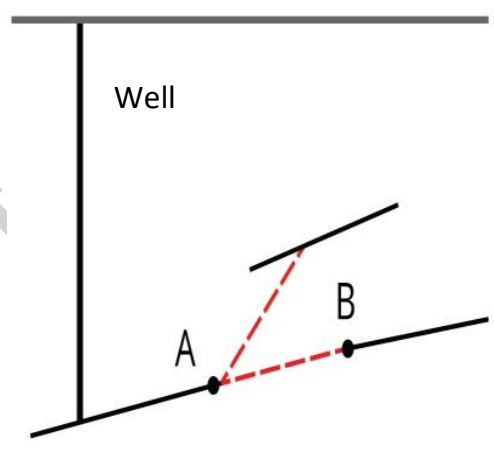

c)

Figure 9 - Conceptual model of persistence (intact rock bridge) effects.

The diagrams show existing fractures with continuous lines and possible interconnections (new fractures) through the intact rock bridges with dashed lines. $a$ and $b$. Instability can occur if the existing fractures are connected with new fractures through the intact rock bridges.

c. Schematic of a well intersecting an existing fracture. Flow to/from the isolated existing factures to the well requires new fractures through the intact rock bridge. 


\section{GEOFRAC - Stochastic Fracture Pattern Model}

GEOFRAC' s stochastic processes are implemented and optimized in MATLAB.

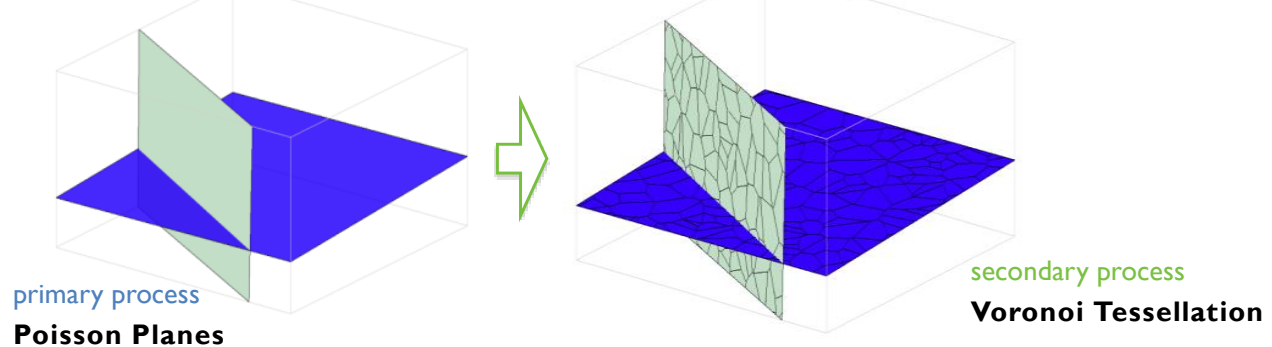

Poisson Planes

tertiary process

Rotation and

Transalation

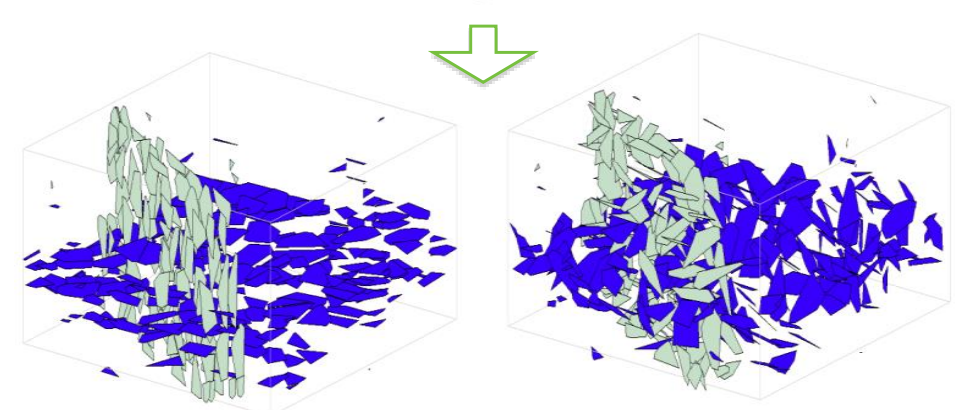

Figure 10 Modeling Geometry with the stochastic DFN model GEOFRAC (after Ivanova et al. 2014)

GEOFRAC can represent fractures and intact rock bridges. This is done by a stepwise process:

- Modeling fracture planes representing fracture orientation distributions (primary process);

- modeling fractures and intact rock using Voronoi tessellation and fracture intensity measures such as $\mathrm{P}_{32}$ (secondary process);

- then rotating and translating the individual fractures (tertiary pocess). 


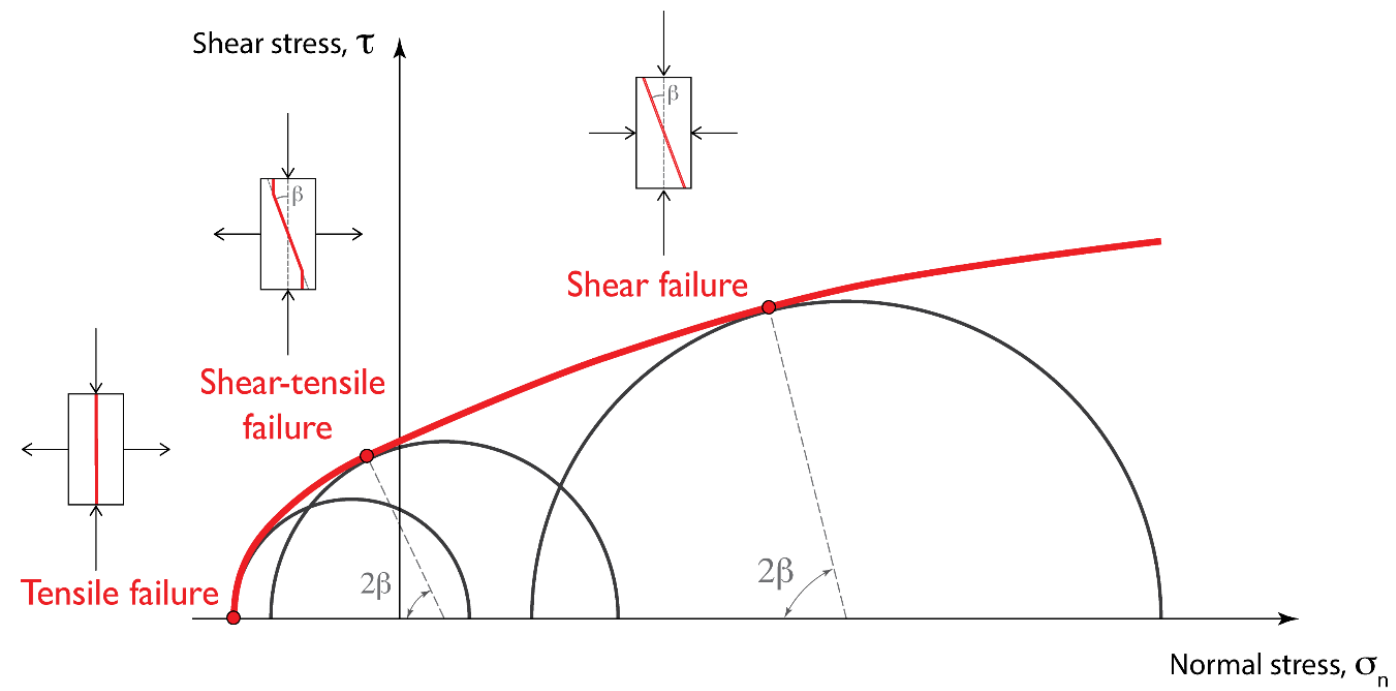

11 Modeling Mechanics - Different mechanisms (after Lajtai, 1969)

Figure 


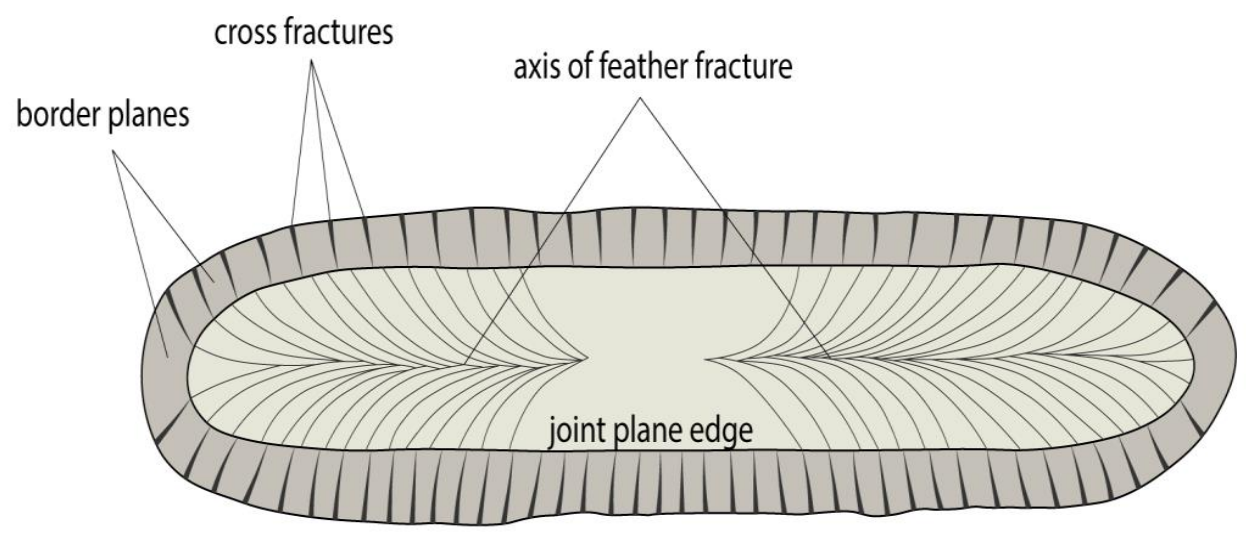

Plan view of Joint (fracture) - with features noted by Woodworth

Figure12 Typical fractography of a tension joint in Cambridge Argillite (after

Woodworth, 1896) [Similar fractography will be seen in Figures 13 and 14 and on tensile fractures produced in laboratory experiments - see Figure 21]. 


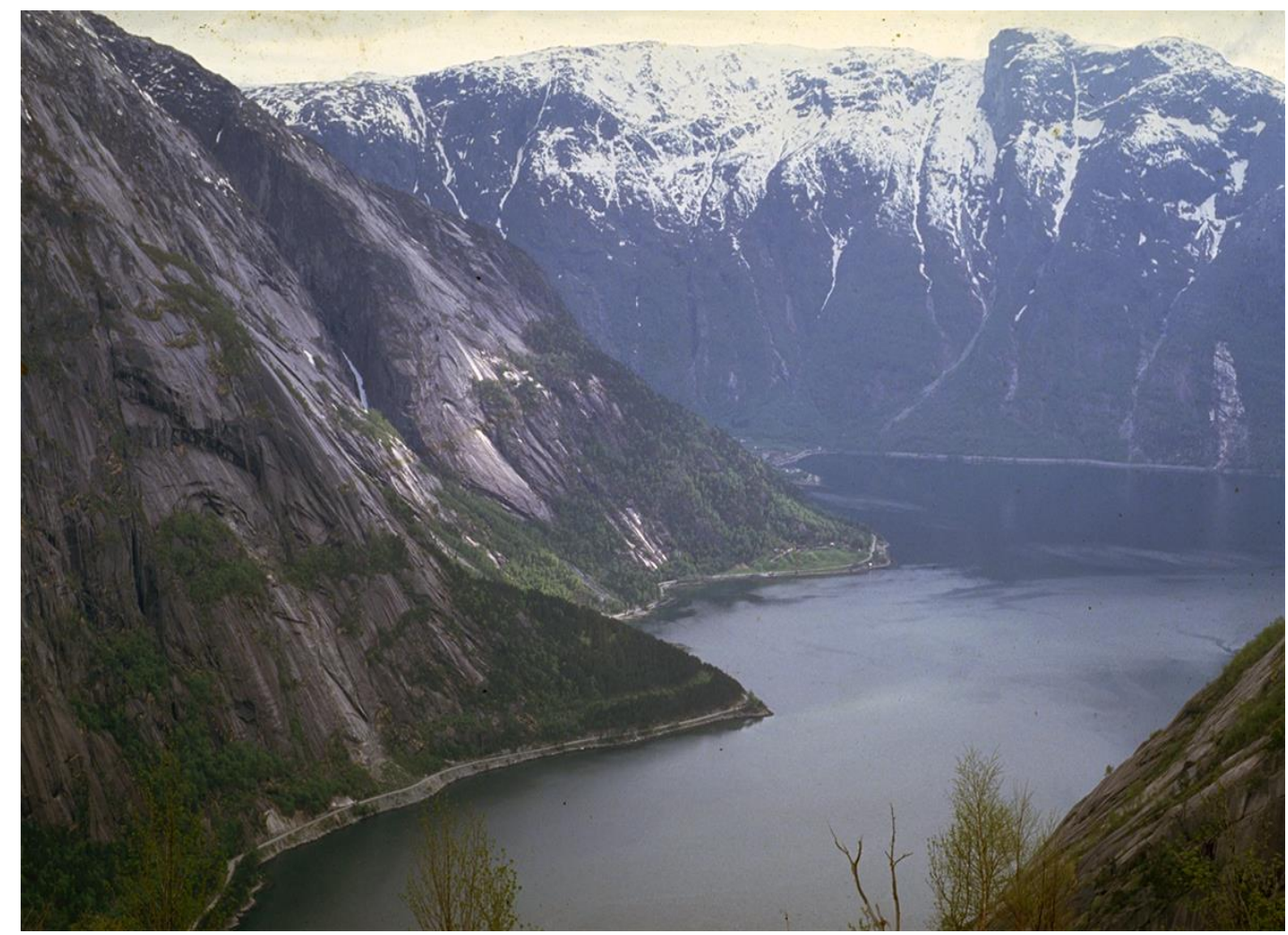

Figure 13 Tensile fracturing in the slopes along Eidfjord Norway - overview. The photo shows that the fracturing has been caused by glacial valley cutting followed by stress relief after the glaciers disappeared. 


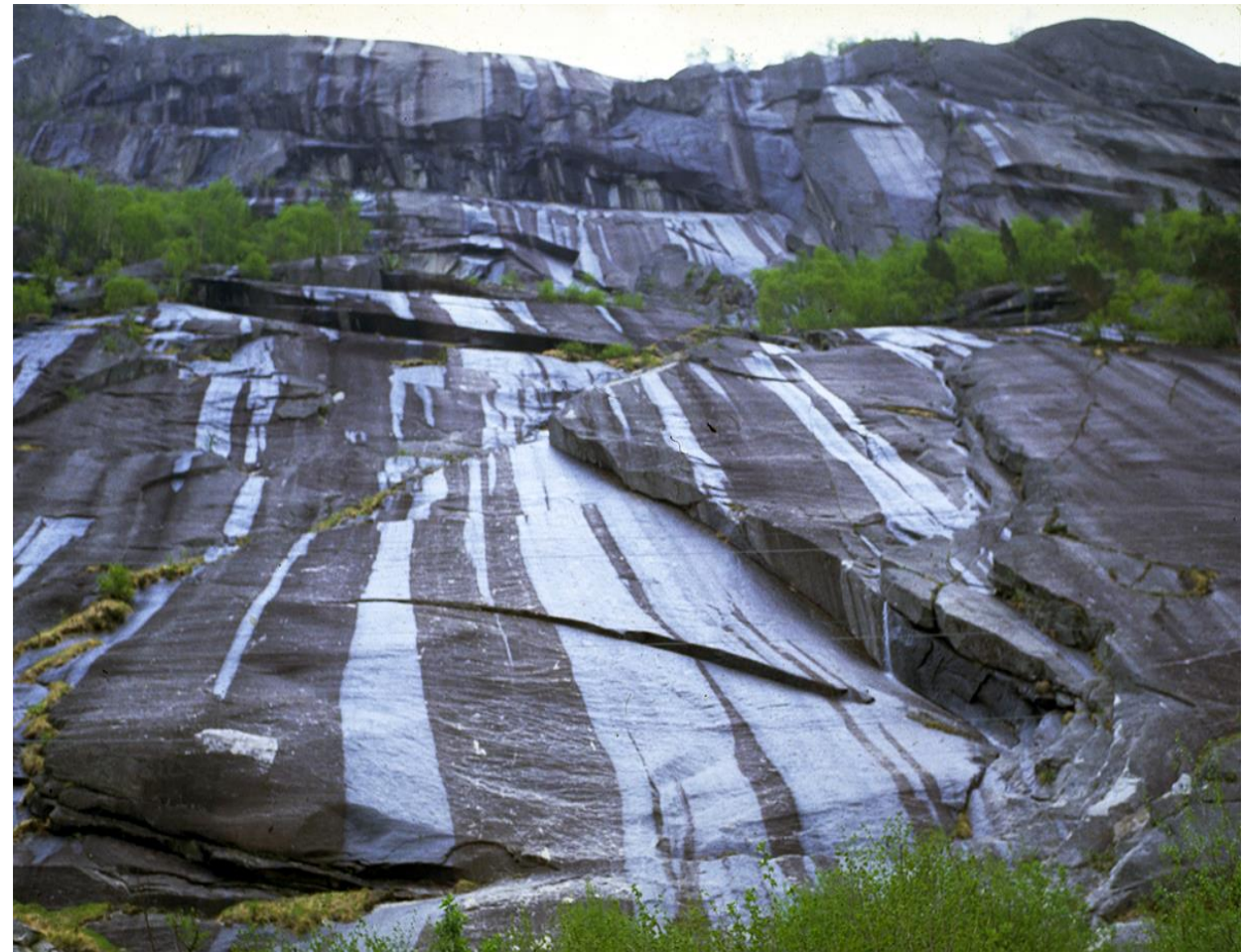

Figure 14 Tensile fracturing in the slopes along Eidfjord Norway - closeup The photo shows the typical tensile fractography of figure 12 but larger 


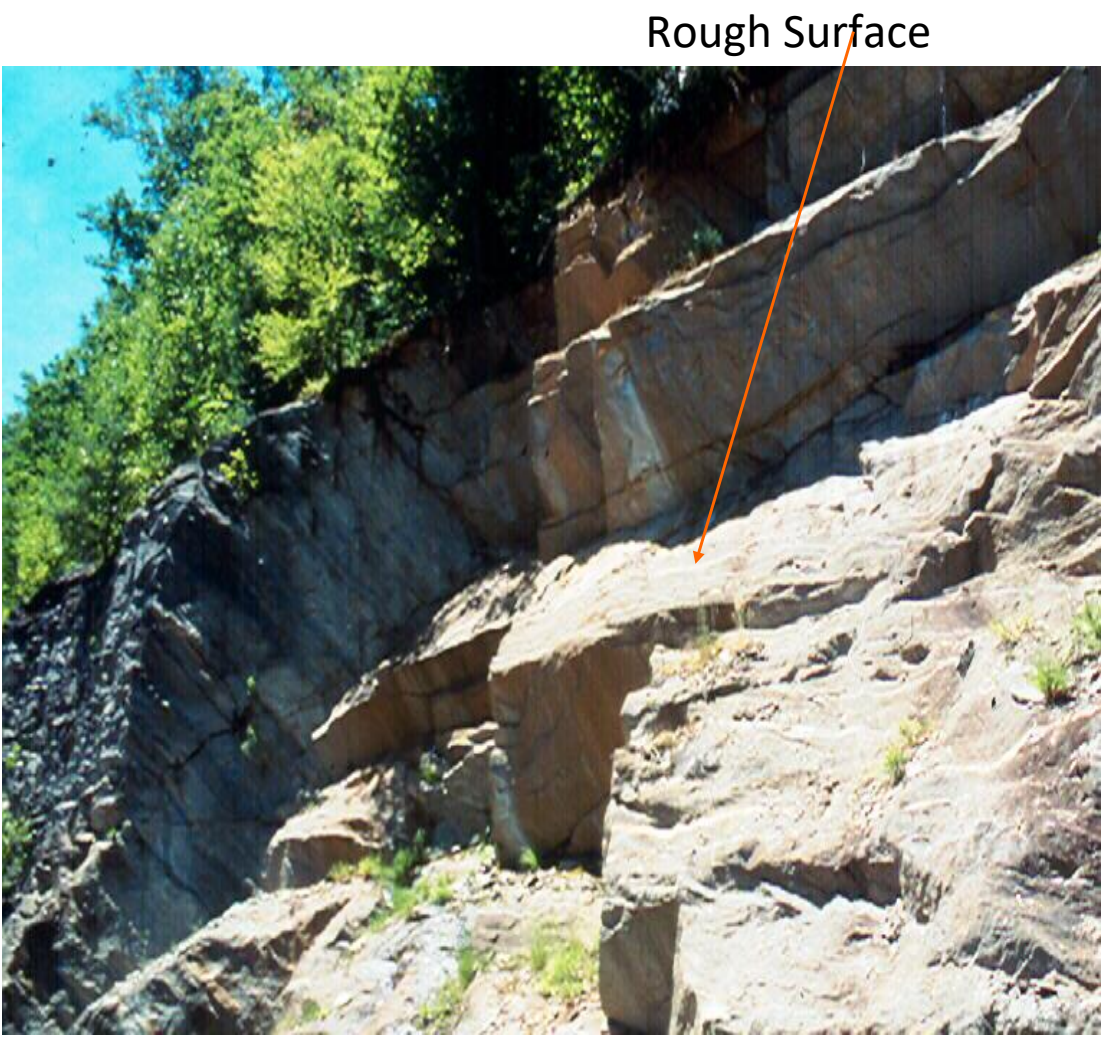

Figure 15 Rough surface - the inclination of the surface indicates that it was probably created by sliding in shear. 


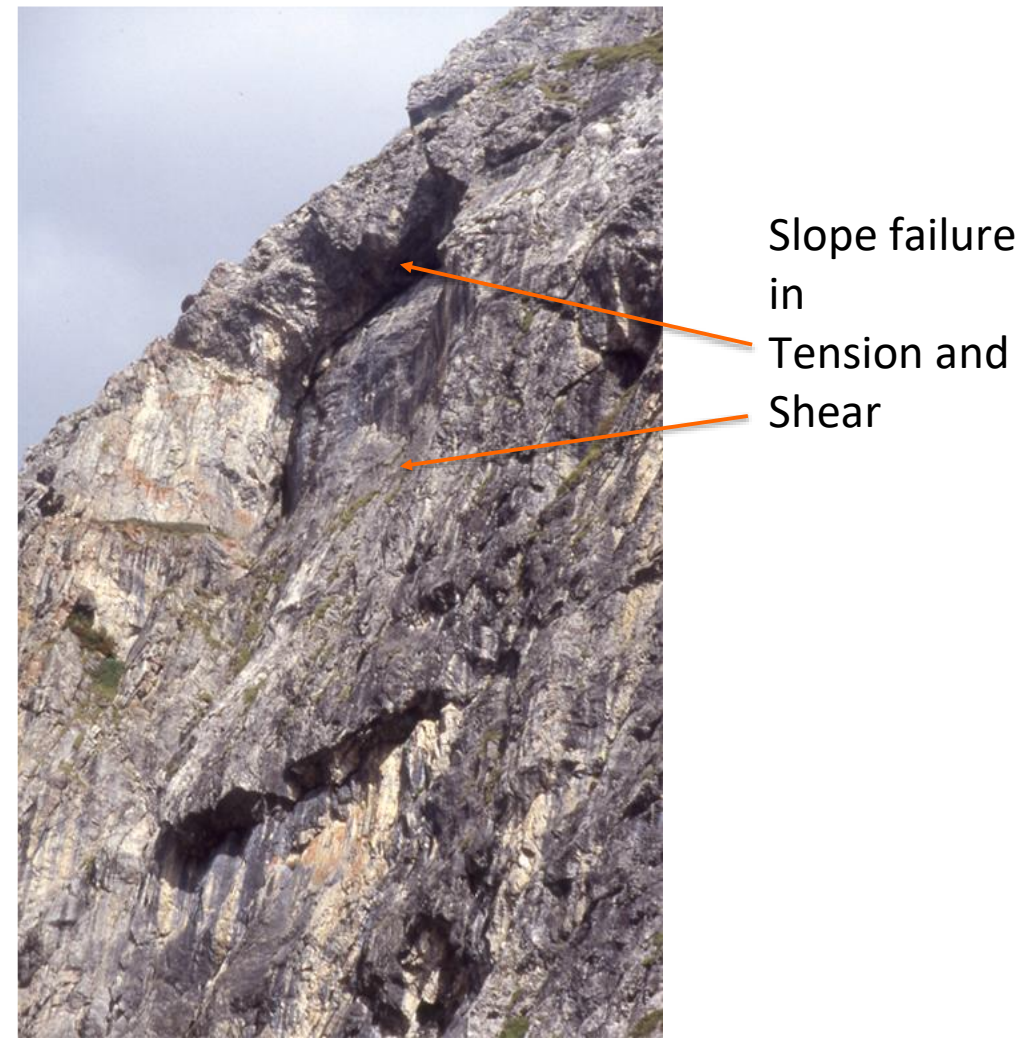

Figure16 Combined shear/tensile failure in a natural slope 


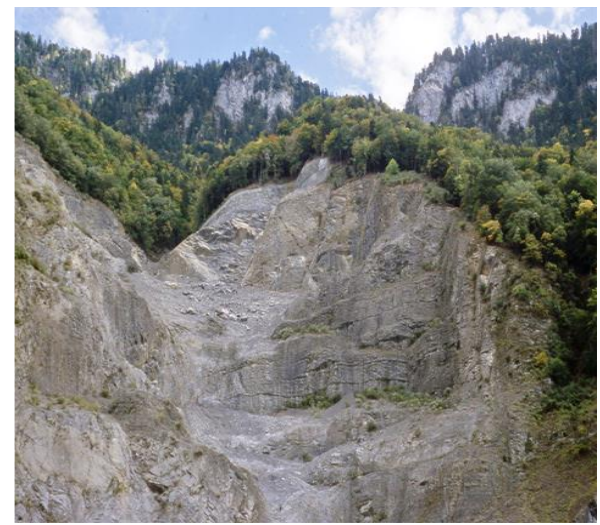

Quarry Slope:

Overview

Quarry Slope:

Close-up

Failure on multiple

differently oriented

surfaces

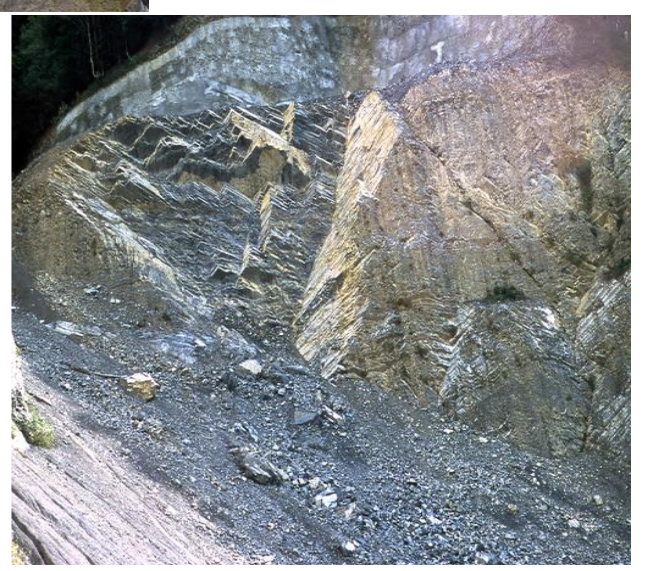

Figure 17 Combined shear/tensile failure in a quarry slope 


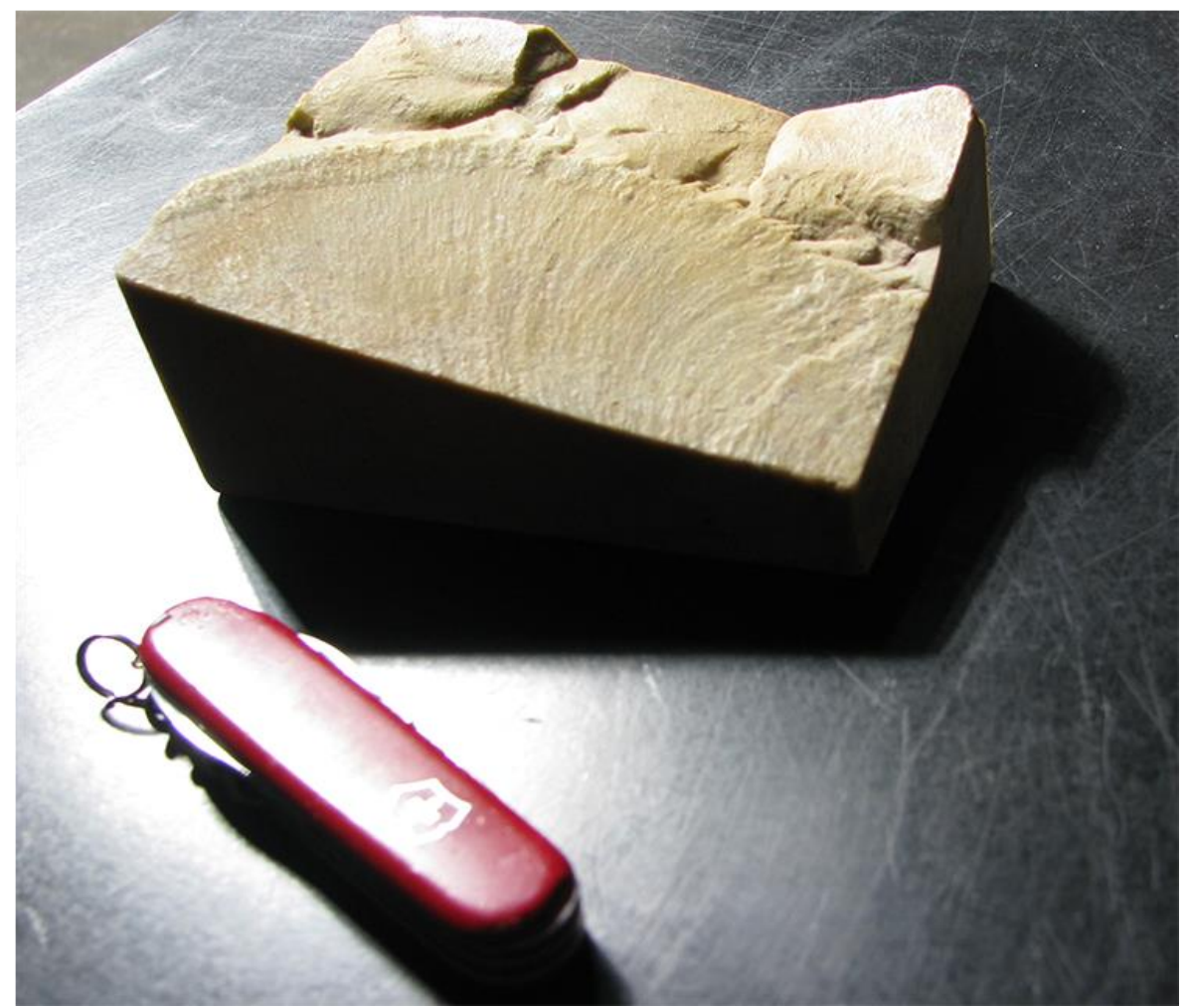

Figure18 Tensile fractography in laboratory experiment 


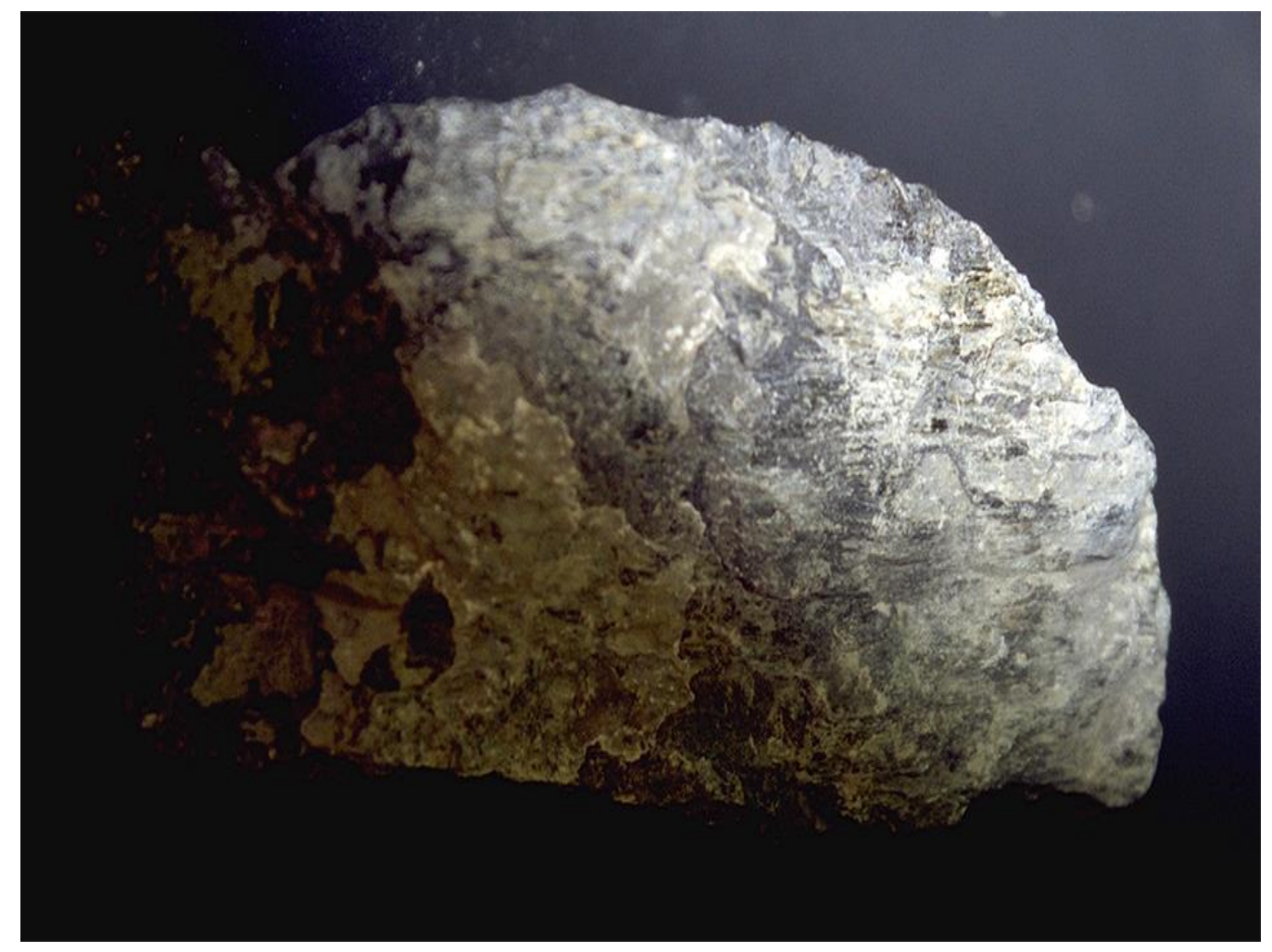

Figure 19 Slickensides (shear) on a hand sized piece 


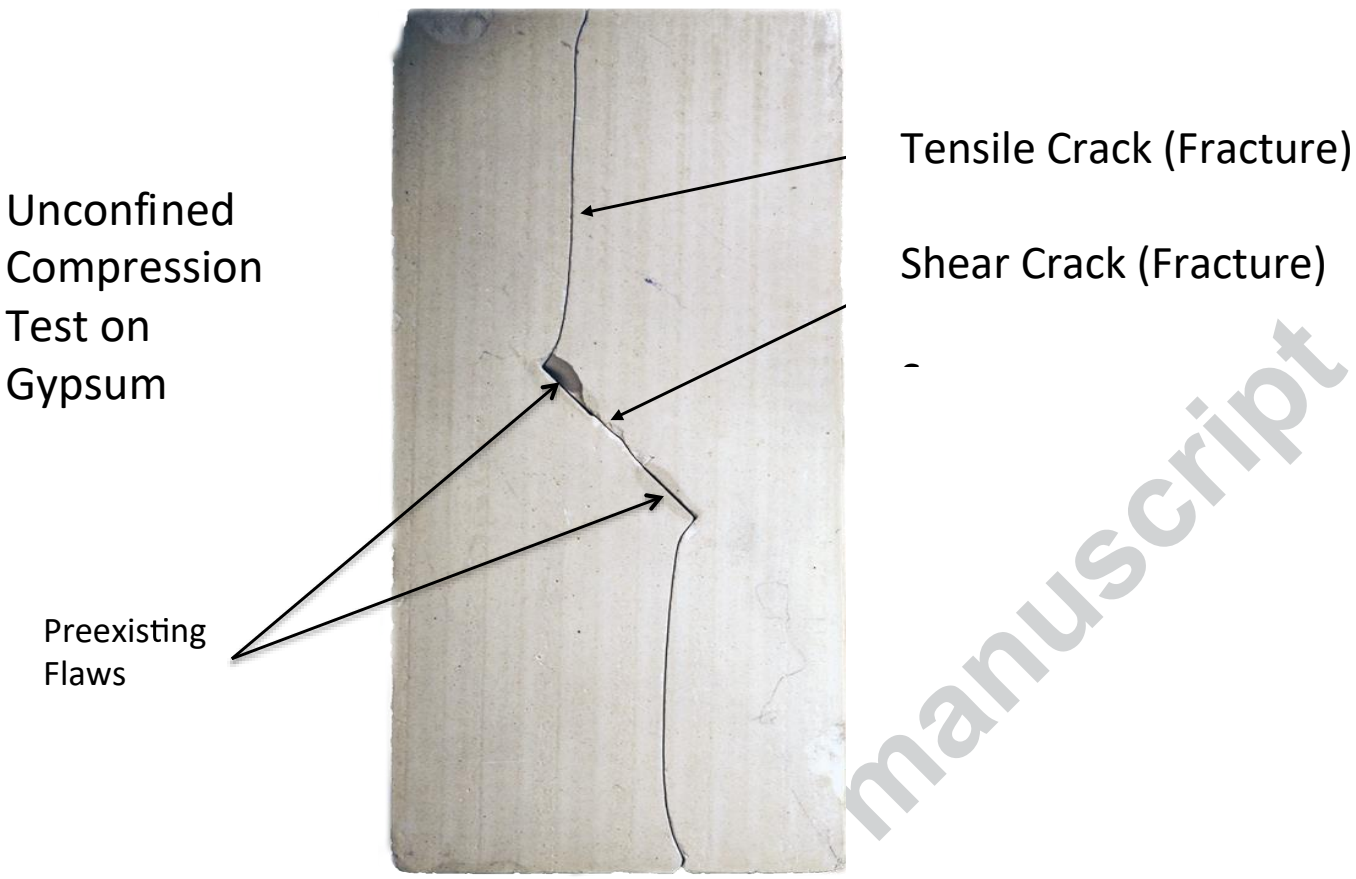

Figure 20 Prismatic gypsum specimen $10 \times 5(\times 2.5) \mathrm{cm}$ with preexisting flaws $(\mathrm{I}=1.25 \mathrm{~cm})$ subjected to uniaxial stress in vertical direction. Failure in tension and shear 


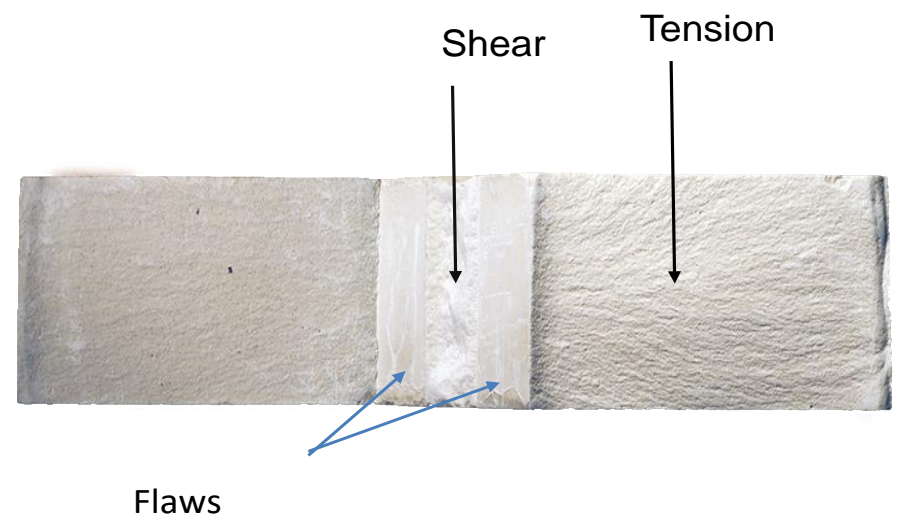

View of failure surface showing shear and tensile fracturing

Figure 21 View of fractography of specimen shown in Figure 20 Note plumose features characterizing tensile fracture 


\section{MOVEMENT}

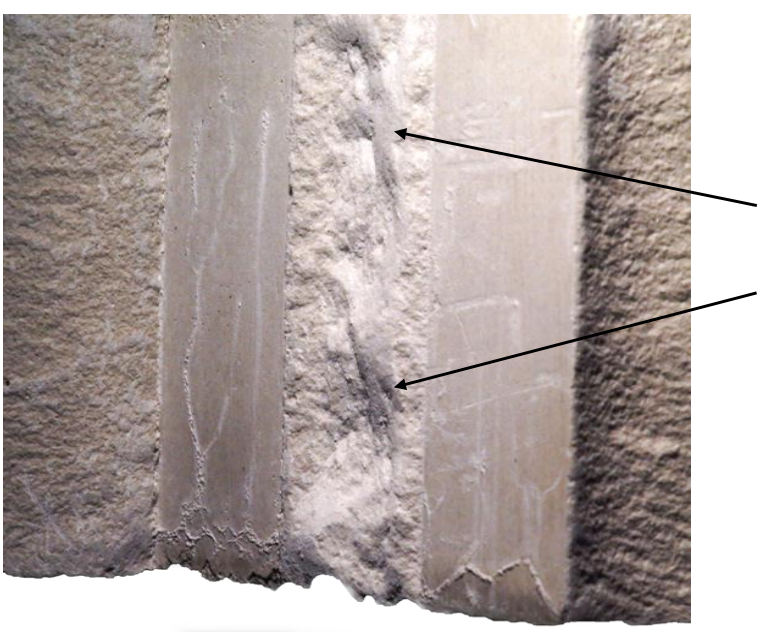

Steep

flank of

steps

AGAINST

movement

Unconfined Compression Test on Gypsum

Closeup view of shear failure surface

62

Figure 22 Close-up view of slickenside-fractography of specimen shown in

Figure 20. Note steps in shear fracture - steep side against movement 


\section{DIRECT SHEAR TESTS by Riedel (1927) on 5cm thick claysheet}

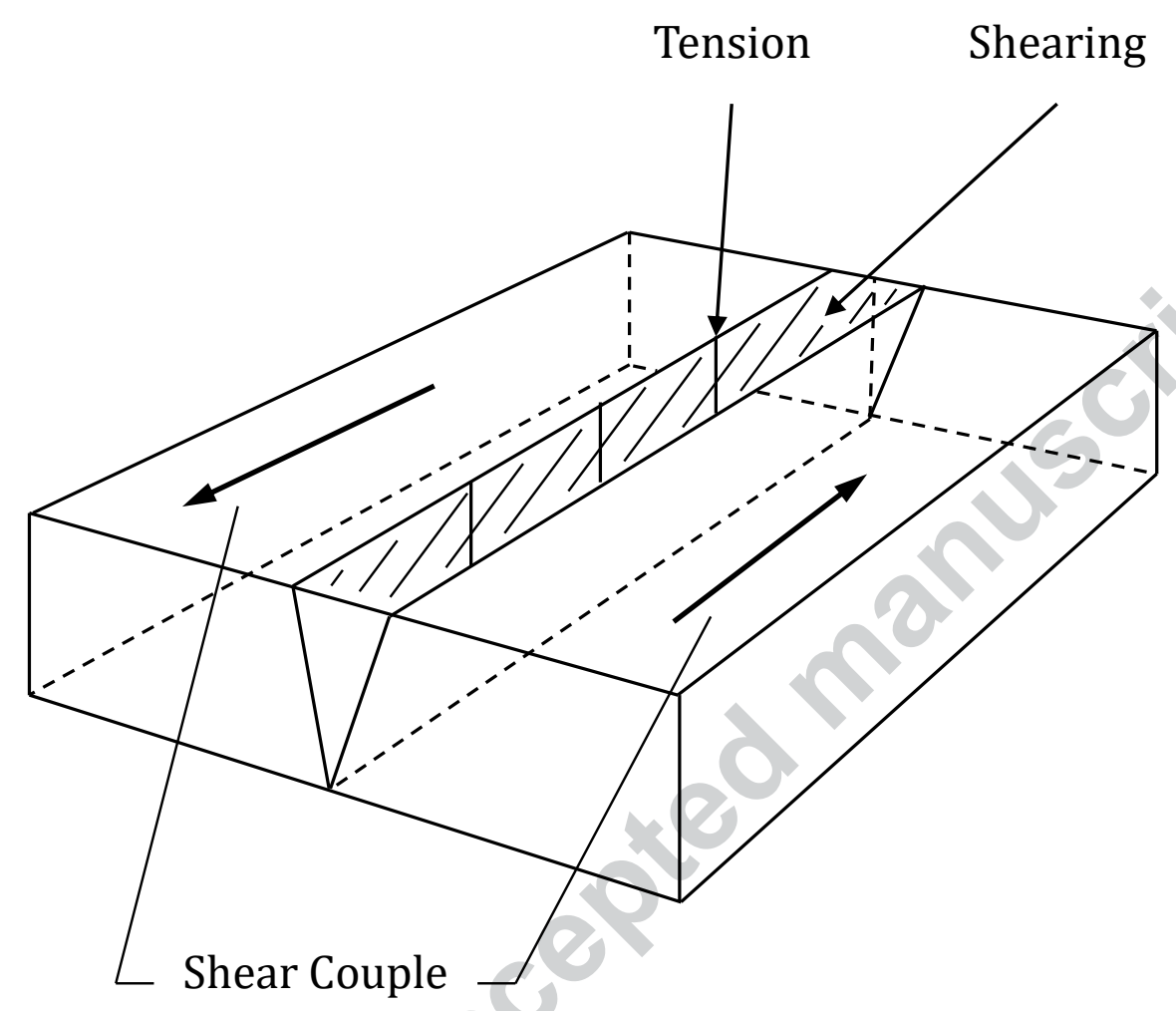

Figure 23 Direct shear tests by Riedel (1927) 


\section{PURE SHEAR TESTS by Cloos (1955) on 5cm thick clay sheet}

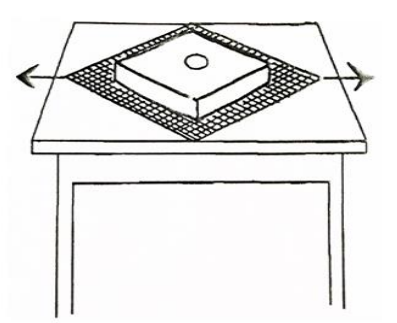

Setup for non-rotational deformation

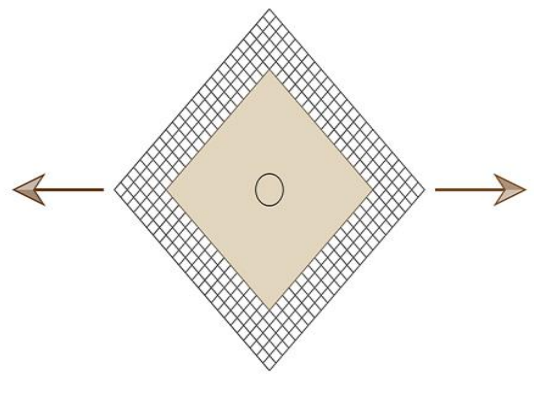

Pure shear

Figure 24 Pure Shear tests by Cloos (1955) (note circle on specimen surface) 


\section{RESULTS: WET CLAY Riedel (1927) Direct Shear}
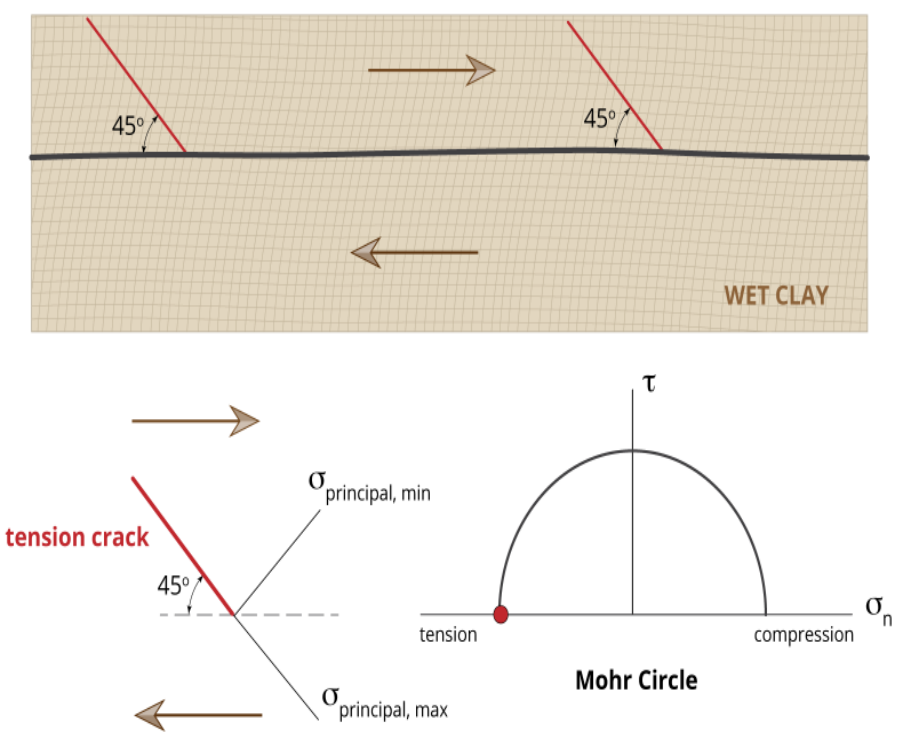

Figure 25 Results of Riedel's direct shear test on wet clay

Tensile cracks 


\section{RESULTS: DRY CLAY Riedel (1927) Direct Shear}

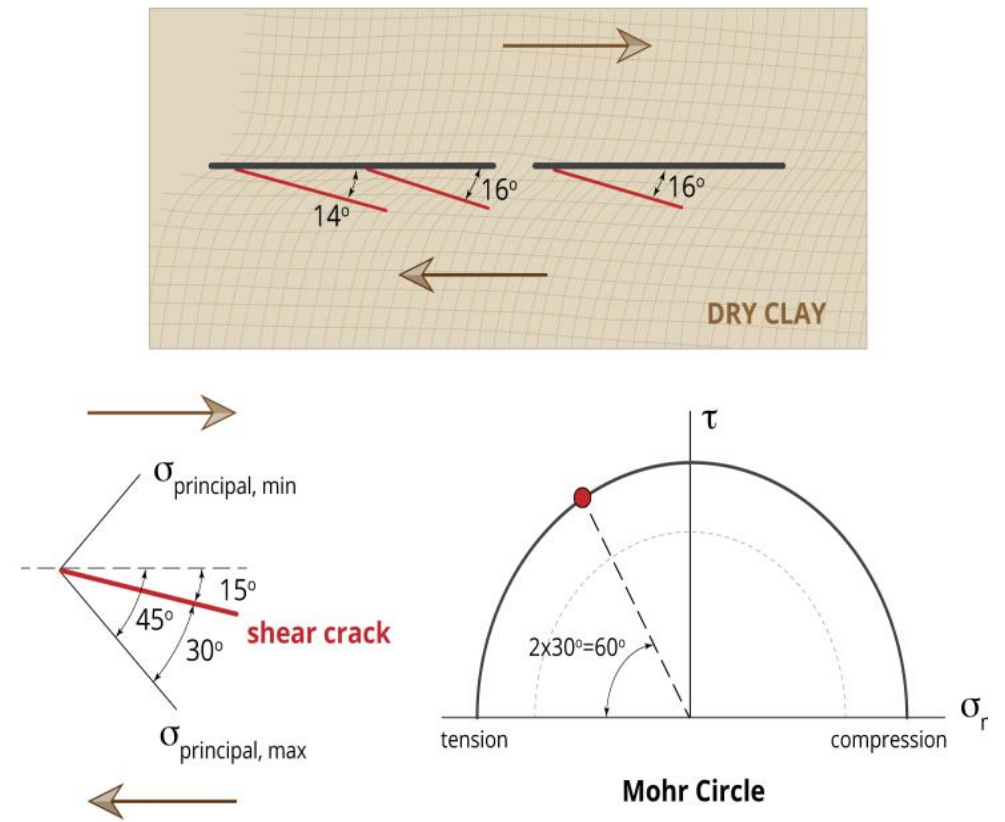

Figure 26 Results of Riedel's direct shear test on dry clay Shear cracks 


\section{RESULTS: Wet Clay \\ Cloos (1955) \\ Pure Shear}
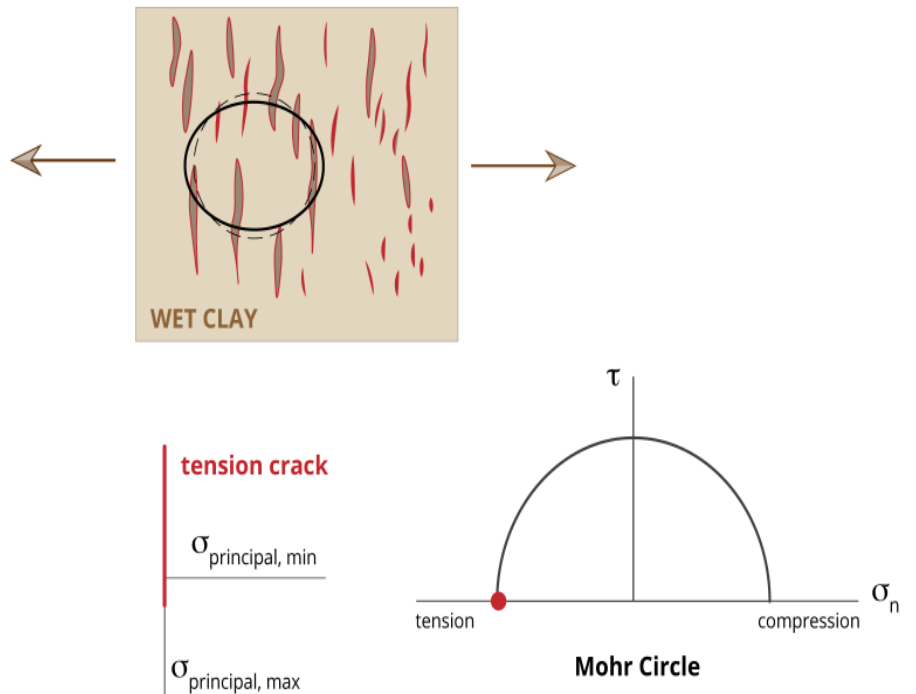

Figure 27 Results of Cloos' pure shear tests on wet clay

Tensile cracks

(Note distorted circle - recall Fig 24 indicating pure shear mechanism) 


\section{RESULTS: Dry clay Cloos (1955) Pure shear}

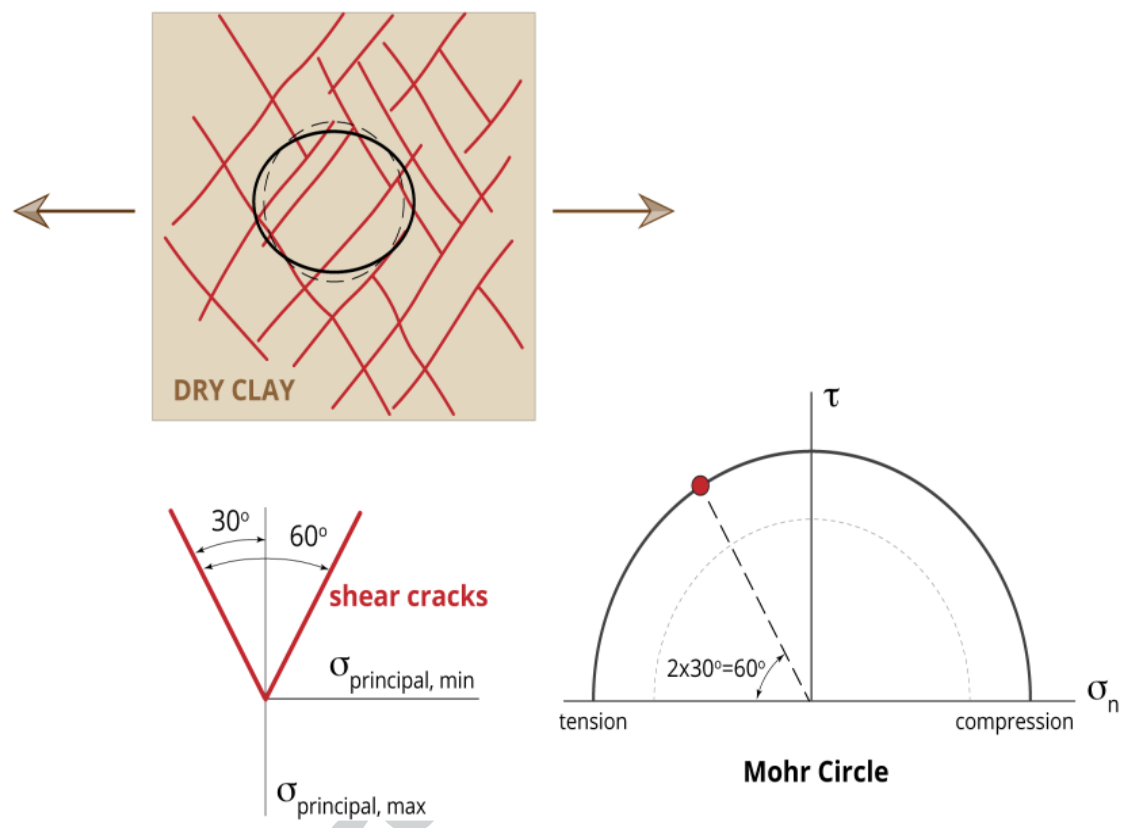

Figure 28 Results of Cloos' pure shear tests on dry clay

Shear cracks

(Note distorted circle -recall Fig 24 indicating pure shear mechanism) 


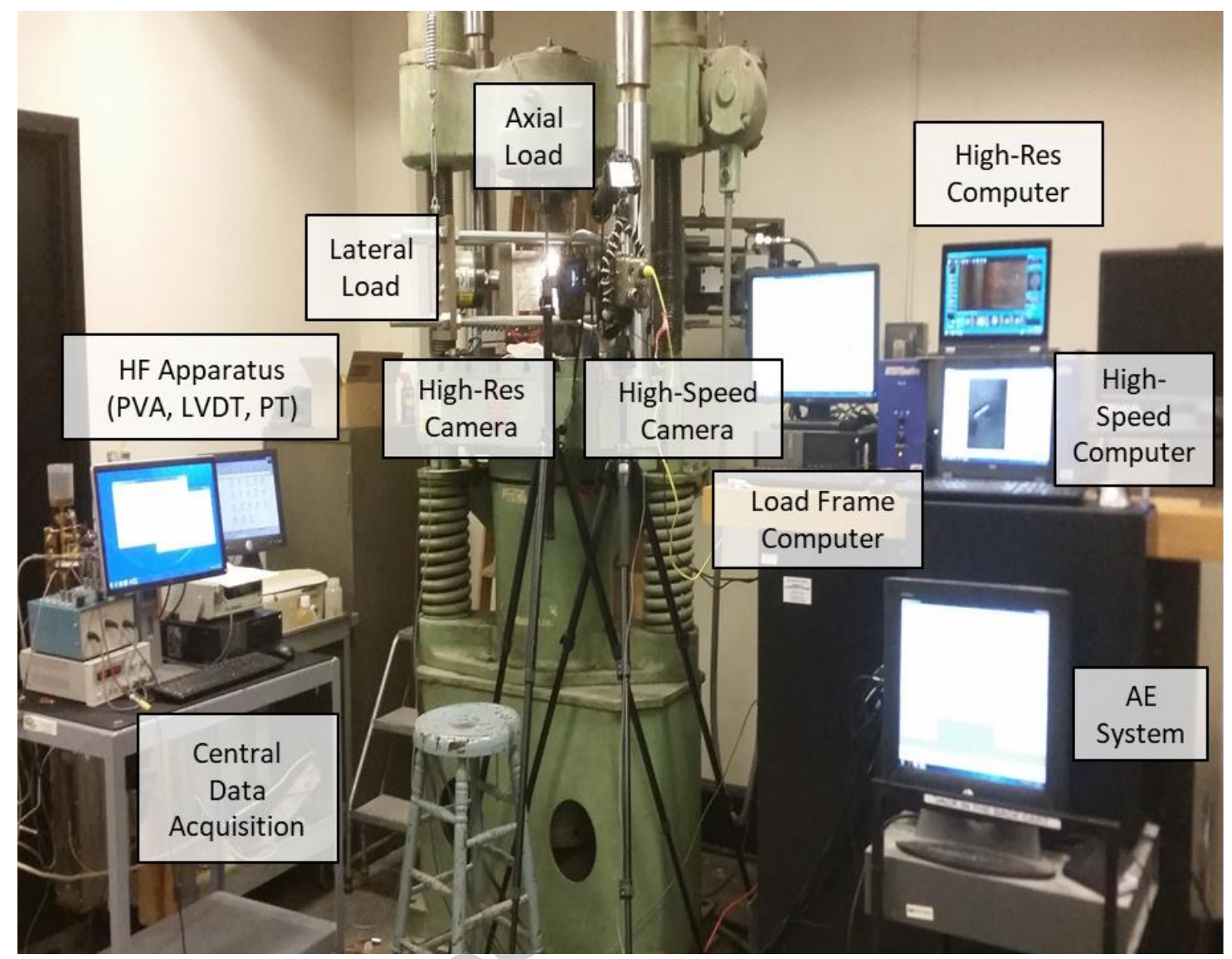

Figure 29 Photo of testing equipment. 


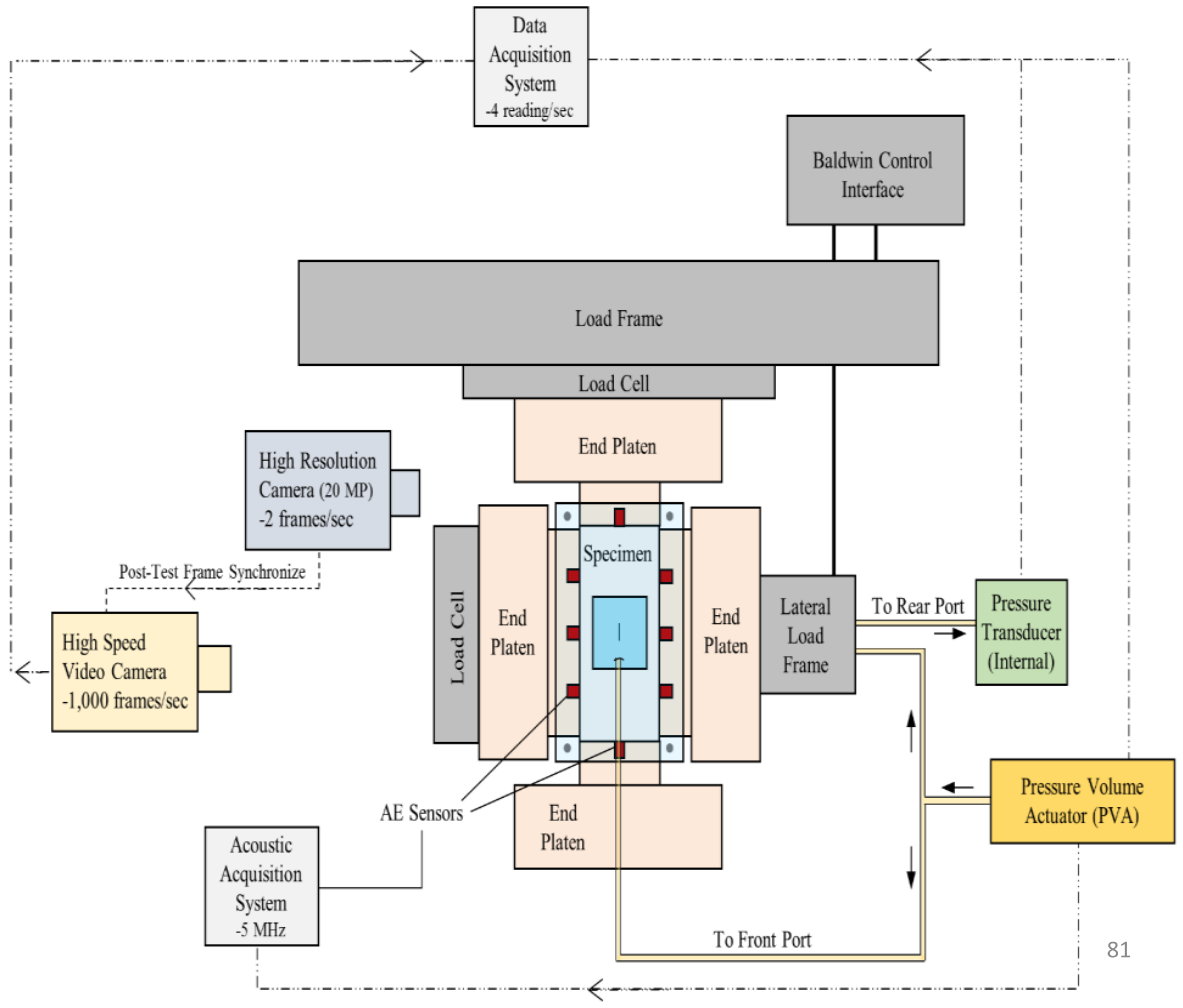

Figure 30 Schematic of testing equipment with control features 


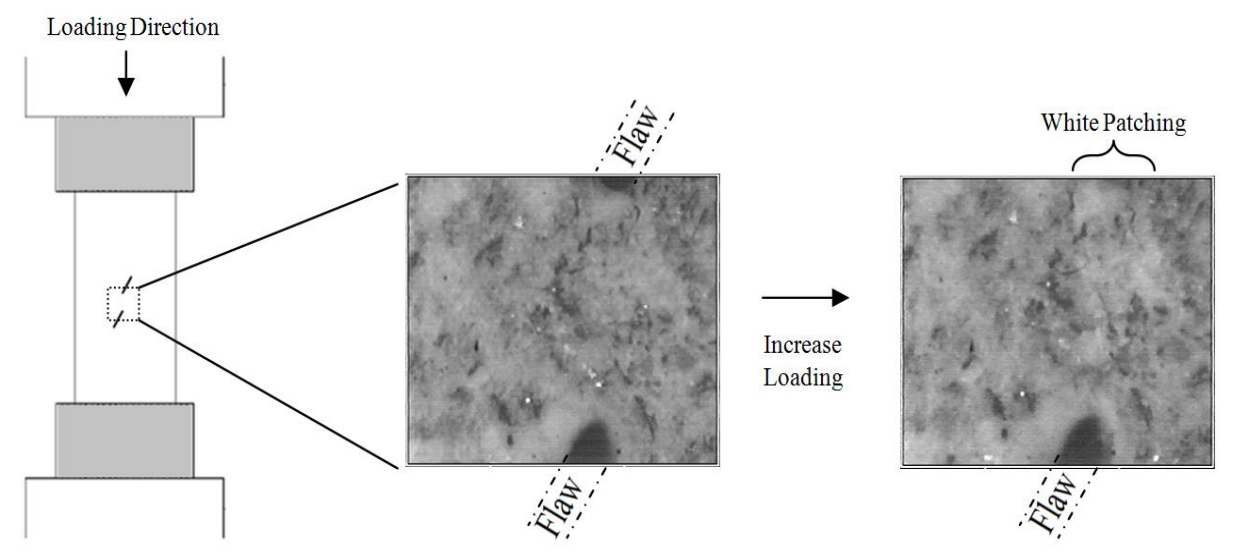

Figure 31 Evolution of "white patching" in granite (from Morgan et al. 2013) 


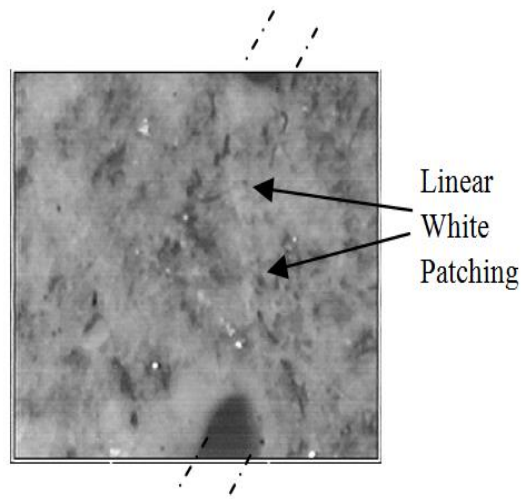

(a)

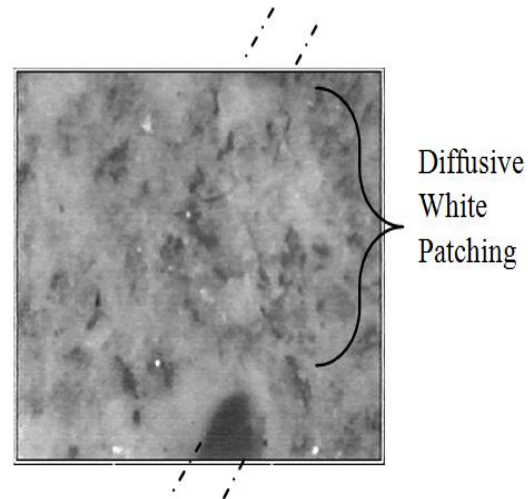

(b)

Figure 32 Linear and diffuse "white patching" in granite (from Morgan et al. 2013) 


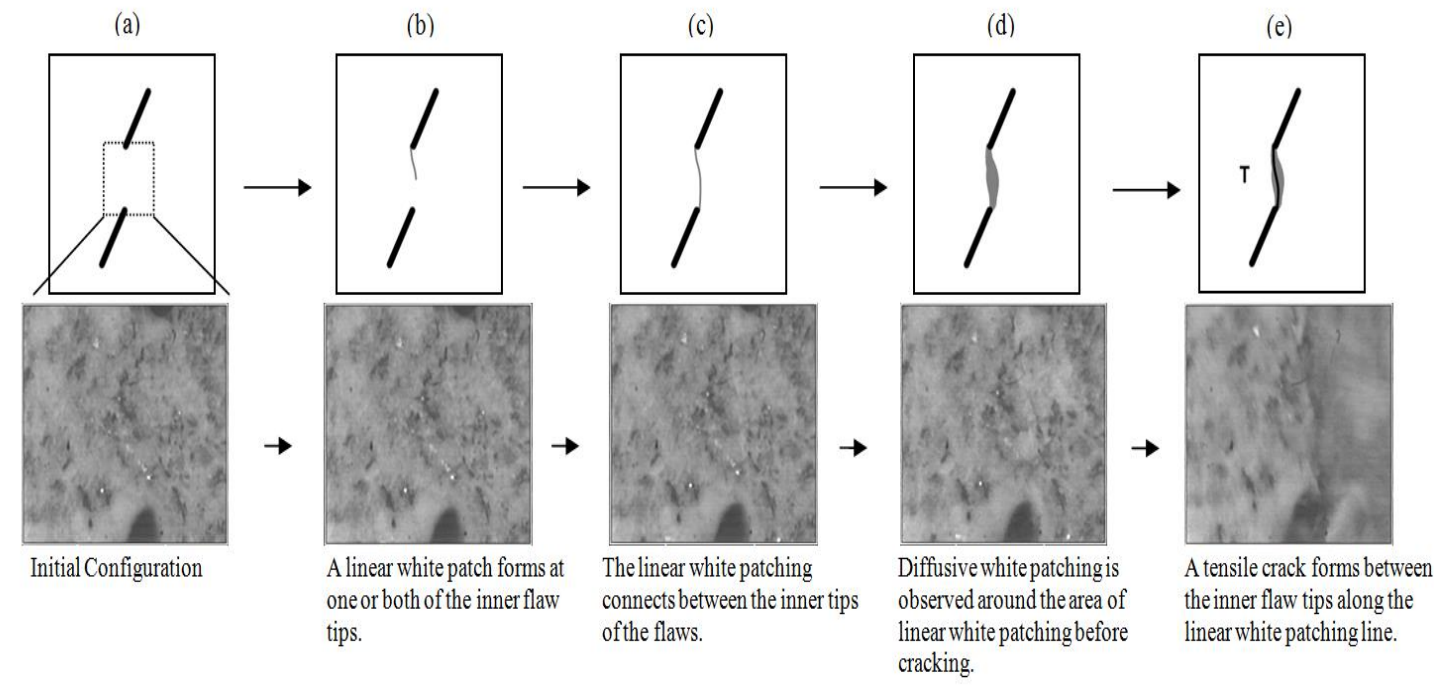

Figure 33 Frame by frame analysis of white patching in granite followed by opening of a crack in tension (from Morgan et al. 2013) 
(a)
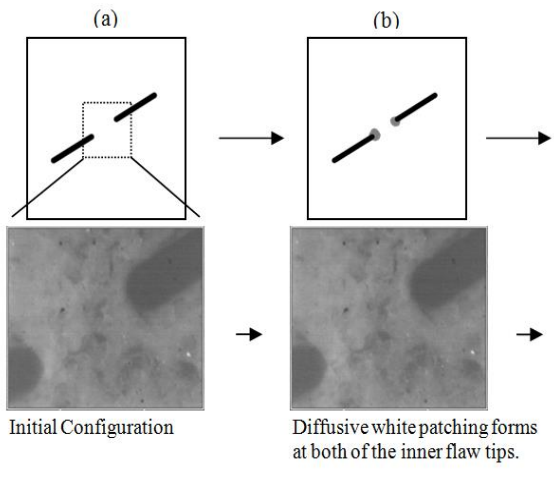

(c)

(d)

(e)

Initial Configuration

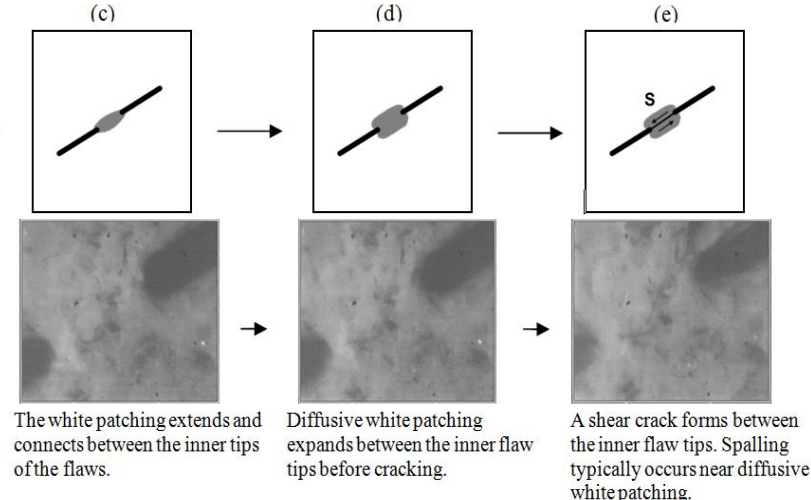

Figure 34 Frame by frame analysis of white patching in granite followed by a shear crack (from Morgan et al. 2013) 


\section{Process Zone in Granite}

Resulting shear crack has shear and tensile features in the process zone

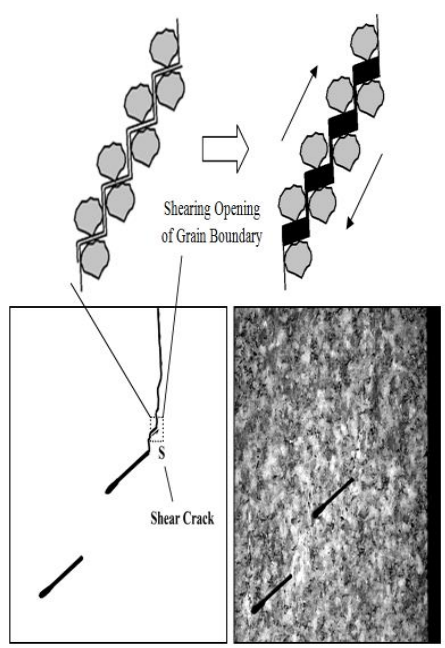

Resulting tensile crack has tensile features and may have shear features in the process zone

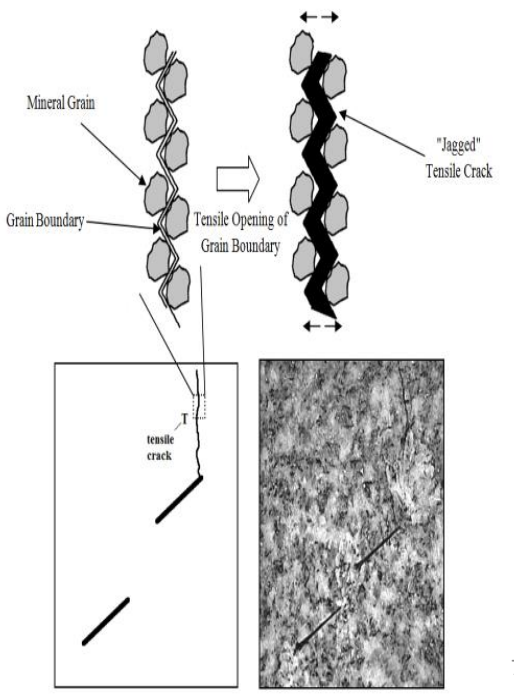

Figure 35 Process zone in granite Investigation with Scanning Electron Microscopy (from Morgan et al. 2013) 
Understand and test tensile cracking process

Four Point Loading Test on Notched Beam - Indirect Tension on both granite and shale
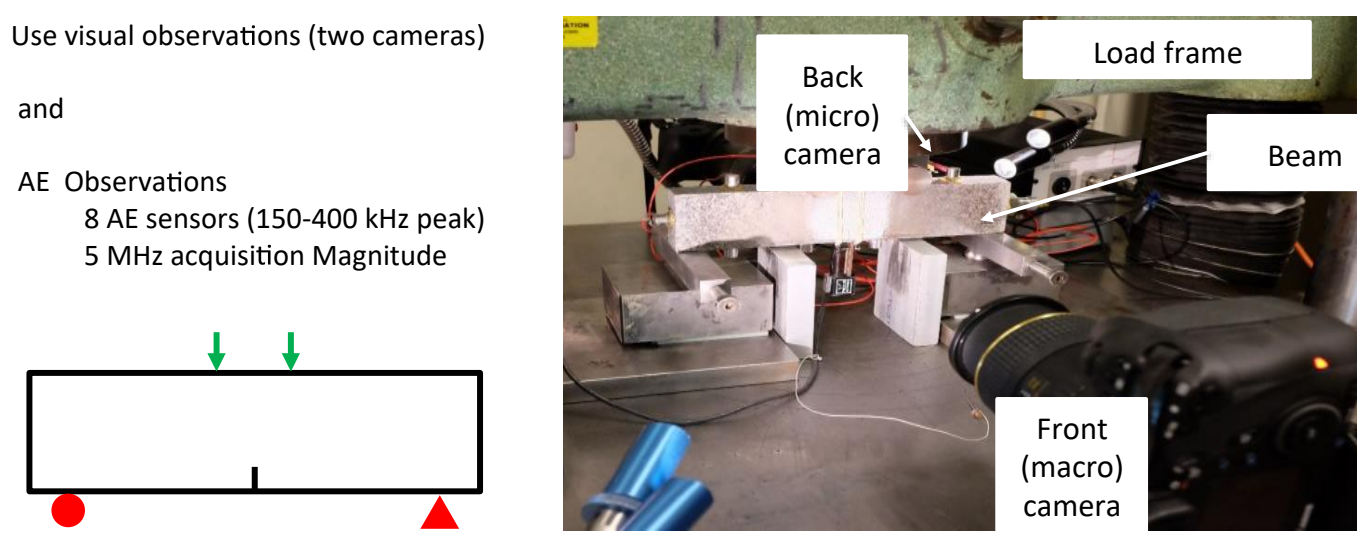

Figure 36 Four point loading test on notched beam

Use of visual observations (two cameras - front macro camera, back micro camera) and AE Observations $8 \mathrm{AE}$ sensors (150-400 kHz peak) $5 \mathrm{MHz}$ acquisition magnitude 
DIC Observations

Shale

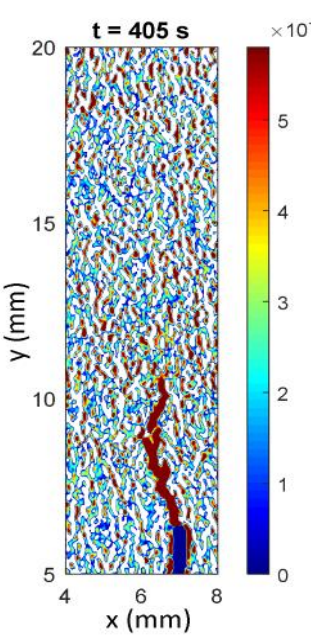

Granite

\section{AE Observations}
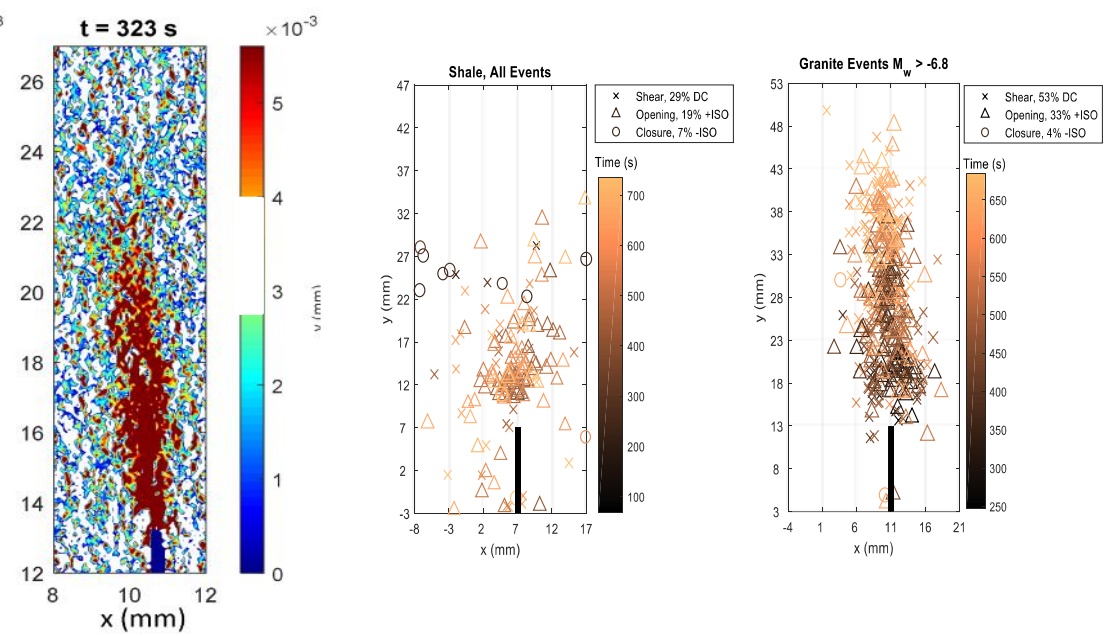

\begin{tabular}{|l|l|c|c|c|}
\hline Material & Loading condition & $\varepsilon_{\mathrm{v}}$ & $\varepsilon_{3}$ & $\varepsilon_{1}$ \\
\hline $\begin{array}{l}\text { Barre granite } \\
\text { Opalinus } \\
\text { BMA-2 }\end{array}$ & $\begin{array}{l}\text { Four-point beam } \\
\text { bending }\end{array}$ & 0.0018 & -0.0095 & 0.0111 \\
Four-point beam & bending & 0.0074 & -0.0684 & 0.0727 \\
\hline
\end{tabular}

Figure 37 DIC (Digital Image correlation) and AE (acoustic emission) Observations of progressing microcracking in 4-Point beam-bending tests on granite and shale 


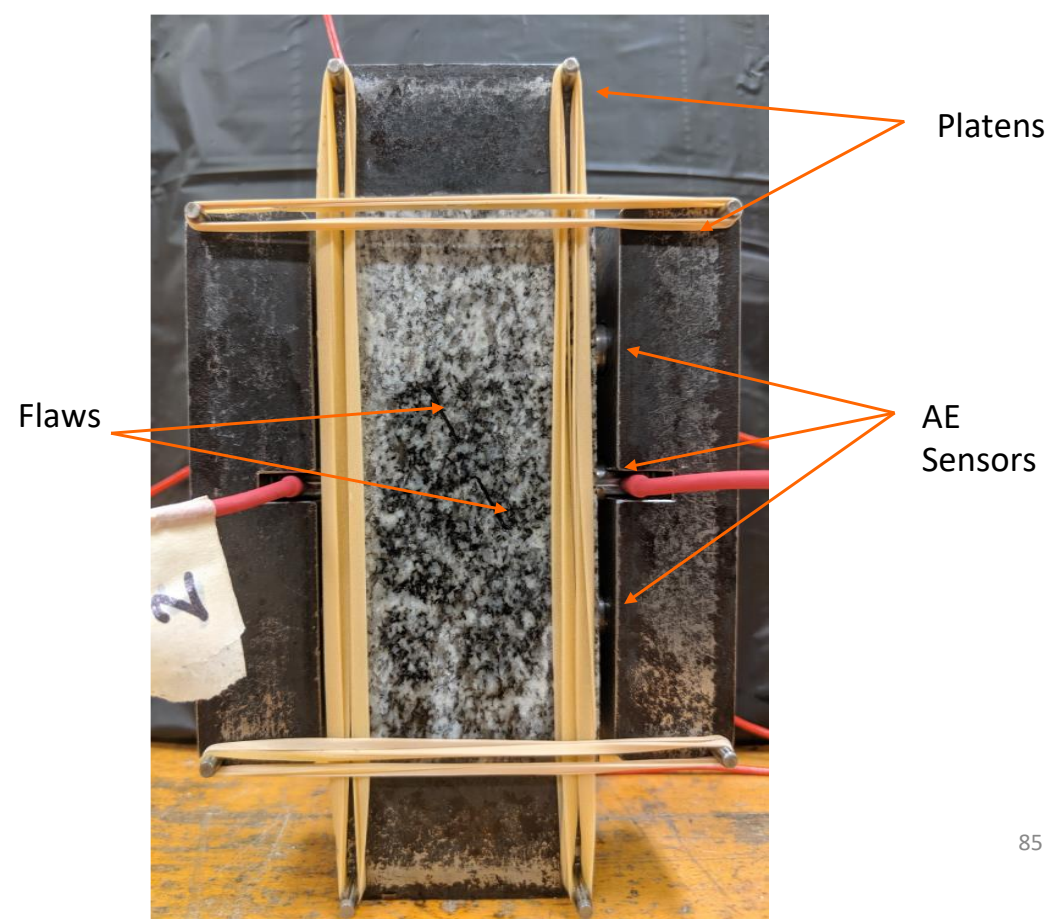

Figure 38 Granite specimen with double flaws, loading platens and AE sensors 


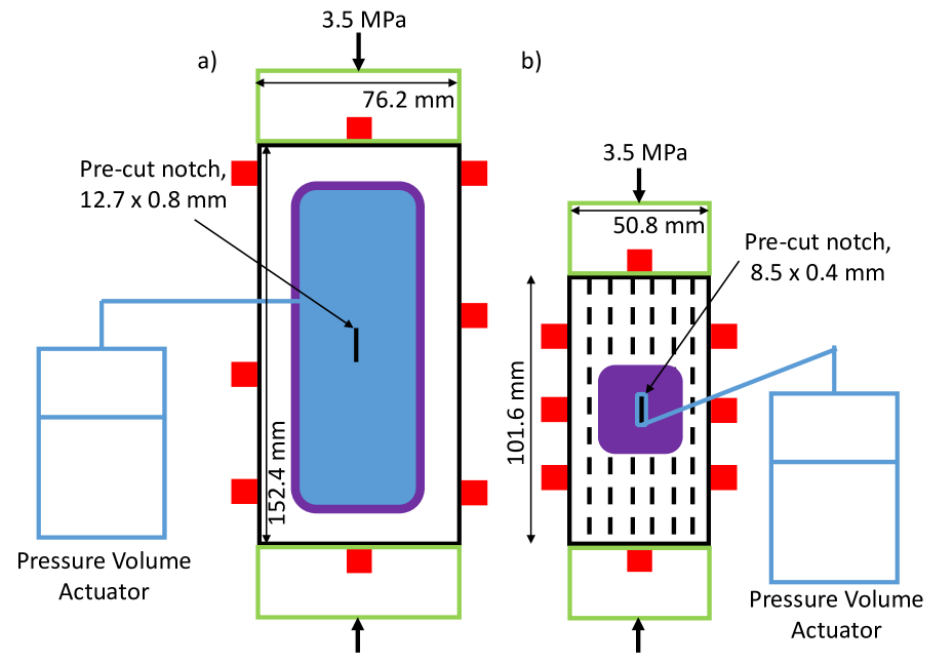

Figure 39 Hydraulic fracturing test on a single vertical flaw 


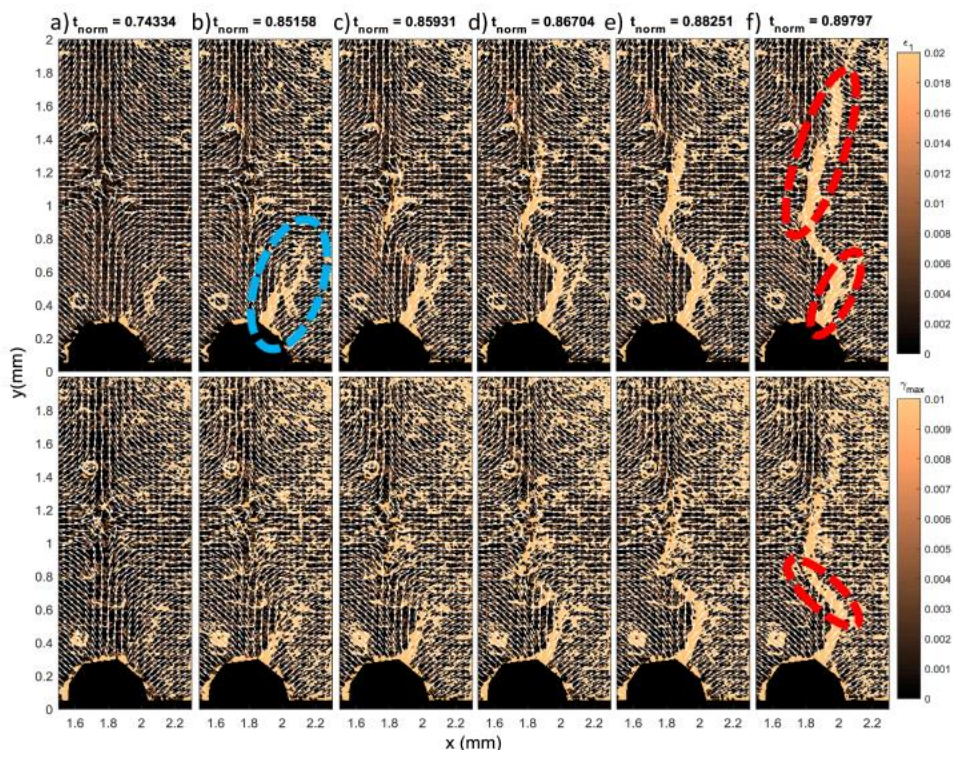

Figure 40 Sequence of crack development in hydraulic fracturing test (Figure 39) visually observed and recorded with DIC 3 


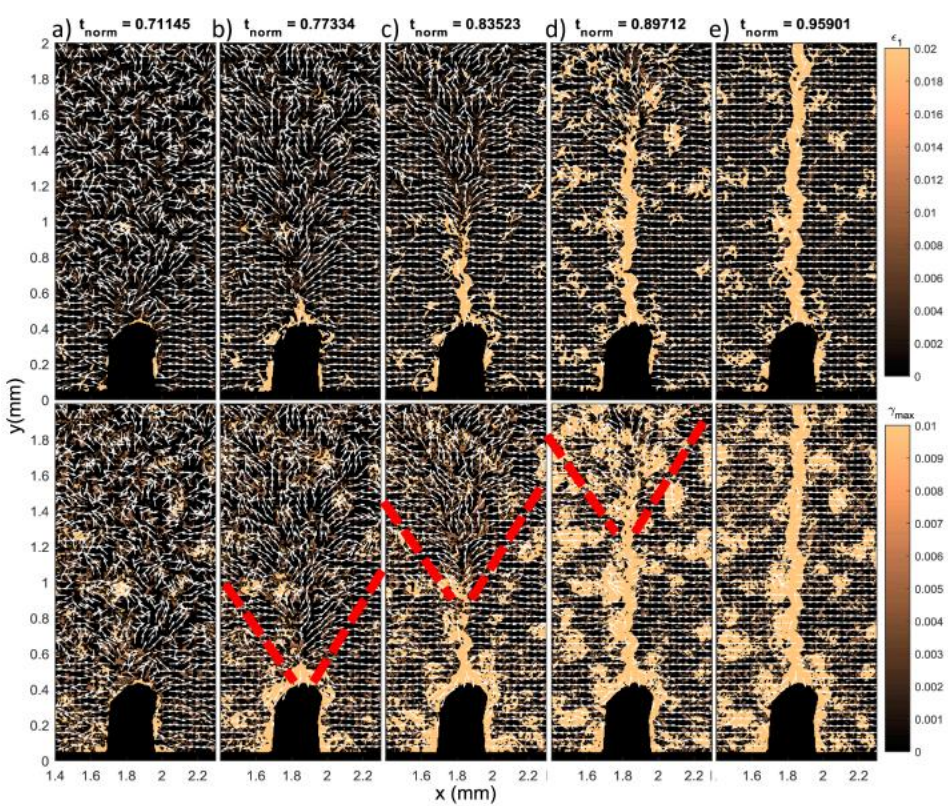

Figure 41 Same sequence as Figure 40 but with identification of wedge shaped strains 

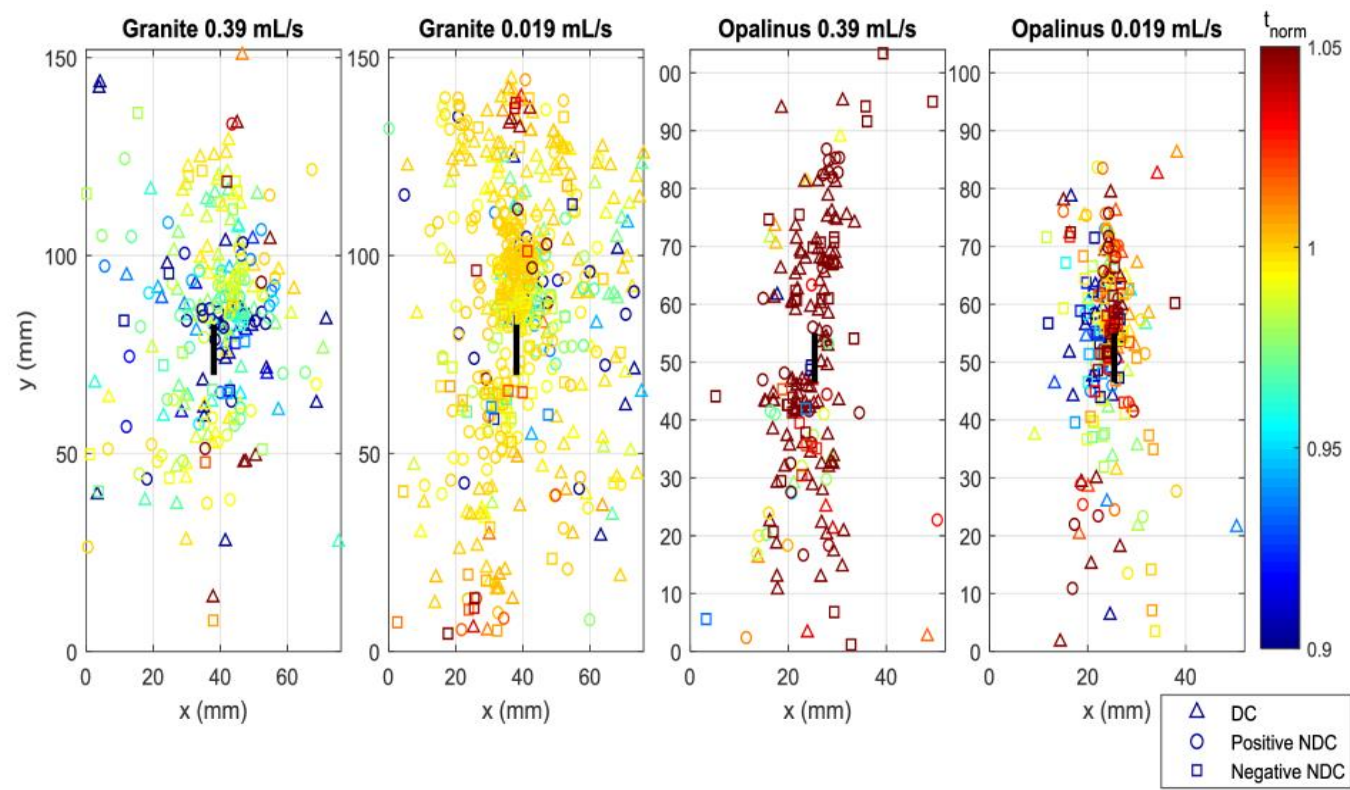

Figure 42 Sequence of crack development of test shown in Figure 40 observed with $\mathrm{AE}$ 